NBER WORKING PAPER SERIES

\title{
STRUCTURAL AND CYCLICAL FORCES IN THE LABOR MARKET DURING THE GREAT RECESSION: CROSS-COUNTRY EVIDENCE
}

\author{
Luca Sala \\ Ulf Söderström \\ Antonella Trigari \\ Working Paper 18434 \\ http://www.nber.org/papers/w18434
}

\author{
NATIONAL BUREAU OF ECONOMIC RESEARCH \\ 1050 Massachusetts Avenue \\ Cambridge, MA 02138 \\ October 2012
}

This paper was prepared for the NBER International Seminar on Macroeconomics 2012. We are grateful to Matthias Hertweck, Alejandro Justiniano, Per Krusell, Fabrizio Perri, Stephanie Schmitt-Grohé, Karl Walentin, as well as participants at the ISOM and the Greater Stockholm Macro Group for comments, to Regis Barnichon and Francesco Zanetti for help with the data, and to Volker Lindenthal for excellent research assistance. The views expressed in this paper are solely the responsibility of the authors and should not be interpreted as reflecting the views of the Executive Board of Sveriges Riksbank or the National Bureau of Economic Research.

NBER working papers are circulated for discussion and comment purposes. They have not been peerreviewed or been subject to the review by the NBER Board of Directors that accompanies official NBER publications.

(C) 2012 by Luca Sala, Ulf Söderström, and Antonella Trigari. All rights reserved. Short sections of text, not to exceed two paragraphs, may be quoted without explicit permission provided that full credit, including $(\odot$ notice, is given to the source. 
Structural and Cyclical Forces in the Labor Market During the Great Recession: Cross-Country Evidence

Luca Sala, Ulf Söderström, and Antonella Trigari

NBER Working Paper No. 18434

October 2012

JEL No. E24,E32

\begin{abstract}
We use an estimated monetary business cycle model with search and matching frictions in the labor market and nominal price and wage rigidities to study four countries (the U.S., the U.K., Sweden, and Germany) during the financial crisis and the Great Recession. We estimate the model over the period prior to the financial crisis and use the model to interpret movements in GDP, unemployment, vacancies, and wages in the period from 2007 until 2011. We show that contractionary financial factors and reduced efficiency in labor market matching were largely responsible for the experience in the U.S. Financial factors were also important in the U.K., but less so in Sweden and Germany. Reduced matching efficiency was considerably less important in the U.K. and Sweden than in the U.S., but matching efficiency improved in Germany, helping to keep unemployment low. A counterfactual experiment suggests that unemployment in Germany would have been substantially higher if the German labor market had been more similar to that in the U.S.
\end{abstract}

Luca Sala

IGIER, Università Bocconi

Via Roentgen 1

20136 Milano

Italy

luca.sala@unibocconi.it

Ulf Söderström

Monetary Policy Department

Sveriges Riksbank

10337 Stockholm

Sweden

ulf.soderstrom@riksbank.se
Antonella Trigari

IGIER, Università Bocconi

Via Roentgen 1

20136 Milano

Italy

antonella.trigari@unibocconi.it 


\section{Introduction}

The financial crisis and the following "Great Recession" had severe consequences for economic activity in most industrialized countries. But labor market outcomes have differed considerably across countries. As an illustration, Figure 1 shows the level of output, the rate of unemployment, the rate of labor productivity, and the labor share since 2005 in four countries: the U.S., the U.K., Sweden, and Germany. ${ }^{1}$ All countries experienced a sharp contraction in GDP from late 2007 until early 2009: the contraction was of a similar magnitude in all countries, but slightly larger in the European countries than in the U.S. Since 2009 all countries have seen a recovery in GDP, but this has been slower in the U.K. and faster in Sweden than in the other countries.

At the same time there are striking differences in the development of unemployment. In the U.S., the unemployment rate more than doubled from 2007 to 2009, and it has only fallen slowly since then. In Germany, unemployment has been falling throughout, with just a small increase during the crisis. Unemployment in Germany is today lower than before the financial crisis. The U.K. and Sweden are in-between, with fairly large increases in unemployment from 2007 to 2009. In Sweden, unemployment has fallen back slightly, while in the U.K. it remains at a much higher level than before 2007 .

The different experiences in terms of output and unemployment are reflected in labor productivity (output per worker), which declined sharply in Germany, the U.K., and Sweden during the crisis, but increased throughout in the U.S. ${ }^{2}$

The final panel of Figure 1 shows the labor share, that is, the ratio of the total wage bill to output or, equivalently, the real wage over labor productivity, in the four countries. ${ }^{3}$ In the U.S. during the Great Recession growth in real wages has lagged behind productivity growth. In contrast, relative to productivity, wages have increased substantially in Germany. ${ }^{4}$ For the U.K. and Sweden, labor productivity has decreased and the labor share has increased, but less so than in Germany.

Another way to study the relationship between output and unemployment is in terms of an Okun's law relationship. Figure 2 plots the yearly growth rate in GDP against the yearly change in the unemployment rate since 1995. The blue (dark) sections of the curves correspond to the period 1995-2007Q1 and the green (light) sections to the period since 2007Q1.

It is clear from this figure that the Great Recession period since 2007 is very different from the earlier period: the points during the Great Recession and subsequent recovery lie far away from the pre-recession points. For all countries but Germany, GDP growth is unusually low in the earlier part of the crisis and unemployment increased substantially.

\footnotetext{
${ }^{1}$ The figure has all variables indexed to 1 in $2007 \mathrm{Q} 1$.

${ }^{2}$ The figure shows the measure of labor productivity that will be relevant when we use the theoretical model to interpret the data. Since we will use data on unemployment, but not on employment, this measure is the ratio of GDP to the difference between a constant labor force and the rate of unemployment.

${ }^{3}$ Similarly to labor productivity, the figure shows the measure of the labor share that will be relevant for the theoretical model.

${ }^{4}$ The initial sharp increase is due at least in part to contracts negotiated in previous years coming into force at the start of 2008 (see, for instance, Burda and Hunt (2011)).
} 
But there is also a change in the relation between output growth and unemployment. The straight lines represent regression lines for the two sub-periods. There was a change in the slope for all four countries, but the change went in opposite directions for the U.S. relative to the other countries. For the U.S., the increase in unemployment was unusually large relative to the fall in output, while the opposite is true for the other countries. ${ }^{5}$

Finally, there are also large differences in the relationship between unemployment and vacancies, the so-called Beveridge curve. Figure 3 shows Beveridge curves for the four countries over the period from 1995 until $2011 .{ }^{6}$ It is well-known that the Beveridge curve in the U.S. has shifted outwards since early 2010, when unemployment has fallen very slowly despite an increase in vacancies, and has only partially moved back. Some commentators have interpreted this as a sign that labor market matching has become less efficient in the U.S. (see, in particular, Kocherlakota (2010)). Sweden also shows signs of an outward shift in the Beveridge curve, while there are no signs of shifts in the U.K. Beveridge curve. In Germany, in contrast, the Beveridge curve seems to have shifted inwards since 2008: for a given level of vacancies the rate of unemployment has decreased.

One possible explanation for these patterns is that different countries were hit by different types of shocks: the U.S. and the U.K. were directly affected by financial shocks, while Sweden and Germany were mainly affected through shocks to the external sector (such as a fall in export demand). Thus, to some extent the differences may be due to cyclical factors. But there are also structural differences across countries that could explain the diverse patterns.

The purpose of this paper is to study the role of structural and cyclical forces in labor market dynamics across these four countries during the financial crisis and the Great Recession. For this purpose we estimate a business cycle model with search and matching frictions and nominal wage and price rigidities on data until 2007. We then use the estimated model to interpret the period from mid 2007 until late 2011. To study the determinants of labor market fluctuations, we compare the structural features of the estimated models and their interpretation of cyclical movements in output, unemployment, and vacancies.

The analysis builds on the model developed and estimated on U.S. data in Gertler, Sala, and Trigari (2008) (henceforth GST). The GST model introduces labor market frictions via a variant of the Diamond, Mortensen, and Pissarides framework into the now conventional monetary business cycle models developed by Christiano, Eichenbaum, and Evans (2005), Smets and Wouters (2007) and others. The variant allows for staggered Nash wage bargaining as in Gertler and Trigari (2009), but in nominal terms. As emphasized by Hall (2012), nominal wage rigidities help reconciling search and matching frictions with the recent behavior of unemployment and inflation in the U.S. when monetary policy has been restricted by the zero lower bound on nominal interest rates.

We differ from GST in a number of aspects. First, we allow for two types of hiring costs: search costs of recruiting new workers, incurred during the process of finding new workers,

\footnotetext{
${ }^{5}$ In the U.S., the estimated slope coefficient increased (in absolute value) from -0.28 before 2007 to -0.5 after 2007, but it fell (in absolute value) from -0.37 to -0.23 in the U.K., from -0.42 to -0.22 in Sweden, and from -0.43 to -0.14 in Germany.

${ }^{6}$ In Figure 3 unemployment is measured directly in terms of the unemployment rate while vacancies are normalized to be 1 in 2008Q4.
} 
and internal costs of adding new workers to a firm's labor force, incurred after the workers and the firm have matched and started an employment relationship. While evidence in Silva and Toledo (2009) and Yashiv (2000) indicates that post-match hiring costs account for a larger fraction of total hiring costs, pre-match costs make hiring costs dependent on the tightness of aggregate labor markets (see Furlanetto and Groshenny (2012a) for a careful analysis of the role of the two costs within a simple New Keynesian model with search and matching frictions). Second, we add to the model a "risk premium" shock that creates a wedge between the risk-free rate and the return on assets held by households and a shock to the efficiency of the matching technology. Both changes are justified by the focus on the Great Recession. The risk premium shock has similar effects as a shock to net worth in models that explicitly model the external finance premium (e.g., Bernanke, Gertler, and Gilchrist (1999) and Christiano, Motto, and Rostagno (2003, 2008)). It has the potential to capture the disruptions in financial markets that have characterized the recent financial crisis. The shock to the matching efficiency may play a significant role in the Great Recession. Changes in matching efficiency have the potential to explain the shifts in Beveridge curves recently experienced in, for instance, the U.S. and Germany (see Furlanetto and Groshenny (2012b) for an analysis of the U.S. experience). However, the effects of matching efficiency shocks on unemployment depend crucially on the importance of pre-match versus post-match hiring costs. With only post-match hiring costs such shocks affect only vacancies without any effect on unemployment. But if pre-match hiring costs are important, also unemployment moves in response to matching efficiency shocks. (See Furlanetto and Groshenny (2012a) for details.) Finally, we differ from GST by including unemployment and vacancies among the set of observable variables used in the estimation instead of total hours worked. Unemployment and vacancies are the two key variables in the model when describing the state of the labor market. ${ }^{7}$

Our analysis proceeds in three steps. After estimating the model on data until 2007Q1, including the key labor market parameters, we first discuss the estimated structural parameters in different countries. Among the key labor market parameters, we find that the relative flow value of unemployment is higher in the U.K. and Sweden than in the U.S., consistently with a higher replacement rate in European countries, but smaller in Germany, possibly due to recent labor market reforms. A second key parameter concerns the weight on pre-match versus post-match hiring costs. Here, we find that post-match hiring costs are completely dominant in the U.K. and Sweden and also very important in the U.S., while the weights are roughly equal in Germany. This helps to account for the shifts in the Beveridge curve in Germany and the U.S.

Next, we interpret movements in the estimated shocks over the sample period as well as the period after 2007. For the U.S., we show that the financial crisis and the Great Recession were characterized by unusually large positive shocks to the risk premium (that is, contractionary financial shocks) and negative shocks to matching efficiency. Also, as monetary policy was restricted by the zero lower bound, our model finds large contractionary monetary policy

\footnotetext{
${ }^{7}$ To facilitate comparability with the literature, GST estimated the model on the same aggregate variables and including the same structural shocks as Smets and Wouters (2007).
} 
shocks after 2008. For the U.K. we also identify contractionary financial shocks and reduced labor market matching efficiency, but in addition we find negative shocks to technology. In Sweden, shocks were rather similar to the U.K., although shocks to financial factors and matching efficiency were less serious. In Germany, we do not find any large shifts in financial shocks or matching efficiency shocks. This pattern is consistent with the impression that Sweden and Germany were less directly hit by financial shocks than were the U.S. and the U.K.

Finally, we interpret the effects of shocks on output, unemployment, and vacancies over the crisis period, and we compare with the period before the financial crisis. For the U.S., our model assigns important roles to financial factors and reduced matching efficiency in the labor market for explaining the fall in output and vacancies and the increase in unemployment after 2007. These factors are considerably more important during the financial crisis and the Great Recession than in the period prior to 2007, and are crucial in understanding the outward shift in the U.S. Beveridge curve. Financial shocks dominate the story also for the U.K., but were relatively less important in Sweden and, in particular, in Germany. Lower matching efficiency mostly affected vacancy posting in the U.K. and Sweden, but had little impact on unemployment. In Germany matching efficiency shocks acted to increase GDP and reduce unemployment. This is possibly a sign that recent labor market reforms in Germany were successful in improving labor market matching.

We also run counterfactual experiments to illustrate how the structure of the labor market contributes to shaping economic outcomes. In particular, we study how output and unemployment would have hypothetically behaved in Germany during the Great Recession if the German labor market had been more similar to the U.S. one. We find that the unemployment rate in Germany would have risen significantly, more in line with the U.S. experience.

Our paper is related to several other recent papers. Justiniano and Michelacci (2012) study labor market dynamics in the same four countries, as well as in France and Norway, within a rich, estimated DGSE model. However, they use a real model without any role for demand-side factors, they model real wage rigidity with an ad-hoc wage rule, do not use data on wages in the estimation and focus on technology shocks. Also, they focus on the period before the financial crisis. They find that technology shocks account for most of the variation in labor market variables in the U.S., while shocks to the matching efficiency and job destruction are more important in European countries.

Galí, Smets, and Wouters (2012) estimate a model that includes unemployment through a reinterpretation of the more standard Smets and Wouters (2007) framework. The use the model to interpret postwar recoveries in the U.S., with special focus on Great Recession. They find that the decline in GDP is mainly due to shocks to the risk premium and investment, but wage setting shocks are an important factor behind the slow recovery in GDP and the persistently high rate of unemployment. In contrast, our framework with search and matching frictions does not assign an important role to wage setting shocks for unemployment in the U.S., this role instead seems to be taken over, at least during the Great Recession, by shocks to the matching efficiency.

Furlanetto and Groshenny (2012a) study how the transmission mechanism of shocks to the efficiency of the matching technology depends on the nature of hiring costs and nominal 
rigidities, and Furlanetto and Groshenny (2012b) estimate a model with search and matching frictions and nominal rigidities on U.S. data to study the role of matching efficiency shocks for the recent U.S. labor market experience. They find that matching efficiency shocks contributed to increase the U.S. unemployment rate by at most one percentage point during the Great Recession, which is broadly consistent with our results. While the empirical exercise they conduct on the U.S. is similar to ours, we differ in a number of aspects: they do not distinguish between an estimation and an evaluation period; they use different observables in the estimation; they do not estimate most of the labor market parameters, and the details of the model differ.

Finally, Christiano, Trabandt, and Walentin (2011) estimate an open-economy model with search and matching frictions and financial frictions as in Bernanke, Gertler, and Gilchrist (1999) and Christiano, Motto, and Rostagno (2003, 2008) on Swedish data until 2010. Their model assigns a more important role to financial shocks for the fall in GDP and increase in unemployment than our model, and a less important role for technology shocks. They also find that in Sweden post-match hiring costs are important than pre-match costs, similar to our results.

Our paper is organized as follows. We develop our model in Section 2. We then discuss the data and our estimation technique in Section 3. In Section 4 we present our results. Finally, we conclude in Section 5.

\section{The model}

The analysis builds on the GST model, which is an evolution of the frameworks in Christiano, Eichenbaum, and Evans (2005), Smets and Wouters (2007) and others. The main difference is the treatment of the labor market. GST introduce search and matching frictions via a variant of the Diamond, Mortensen, and Pissarides framework that has staggered Nash bargaining as in Gertler and Trigari (2009). Importantly, Nash bargaining takes place in nominal terms, rather than over real wages as in Gertler and Trigari (2009).

We here provide a sketch of the model; for more details, see Gertler, Sala, and Trigari (2008). There are only two differences relative to GST. First, the set of shocks included in the model is different: we add a risk premium shock and a shock to the efficiency of the matching technology. But we remove a shock to consumer preference. Second, we allow for a more general hiring cost function that allows for both costs in posted vacancies and costs in filled vacancies or new matches.

There are three types of agents in the model: households, wholesale firms, and retail firms. Following Merz (1995) we assume a representative family in order to introduce complete consumption insurance. Production takes place at competitive wholesale firms that hire workers subject to search and matching frictions and negotiate wage contracts via staggered Nash bargaining. Monopolistically competitive retail firms buy goods from wholesalers, repackage them as final goods, and set prices on a staggered basis. 


\subsection{Households}

There is a representative household with a continuum of members of measure unity. At each time $t$ a measure $n_{t}$ of household members are employed and a measure $1-n_{t}$ are unemployed. Household members are assumed to pool their labor income to insure themselves against income fluctuations. The household consumes final goods, saves in one-period nominal government bonds, and accumulates physical capital through investment. It transforms physical capital to effective capital by choosing the capital utilization rate, and then rents effective capital to firms.

The household thus chooses consumption $c_{t}$, bond holdings $B_{t}$, the rate of capital utilization $\nu_{t}$, investment $i_{t}$, and physical capital $k_{t}^{p}$ to maximize the utility function

$$
\mathrm{E}_{t}\left\{\sum_{s=0}^{\infty} \beta^{s} \log \left(c_{t+s}-h c_{t+s-1}\right)\right\},
$$

where $\beta$ is a discount factor and $h$ measures the degree of habits in consumption preferences. ${ }^{8}$

The capital utilization rate $\nu_{t}$ transforms physical capital into effective capital according to

$$
k_{t}=\nu_{t} k_{t-1}^{p},
$$

which is rented to wholesale firms at the rate $r_{t}^{k}$. The cost of capital utilization per unit of physical capital is given by $\mathcal{A}\left(\nu_{t}\right)$, and we assume that $\nu_{t}=1$ in steady state, $\mathcal{A}(1)=0$ and $\mathcal{A}^{\prime}(1) / \mathcal{A}^{\prime \prime}(1)=\eta_{\nu}$, as in Christiano, Eichenbaum, and Evans (2005) and others.

Physical capital accumulates according to

$$
k_{t}^{p}=(1-\delta) k_{t-1}^{p}+\varepsilon_{t}^{i}\left[1-\mathcal{S}\left(\frac{i_{t}}{i_{t-1}}\right)\right] i_{t},
$$

where $\delta$ is the rate of depreciation, $\varepsilon_{t}^{i}$ is an investment-specific technology shock with mean unity, and $\mathcal{S}(\cdot)$ is an adjustment cost function which satisfies $\mathcal{S}\left(\gamma_{z}\right)=\mathcal{S}^{\prime}\left(\gamma_{z}\right)=0$ and $\mathcal{S}^{\prime \prime}\left(\gamma_{z}\right)=\eta_{k}>0$, where $\gamma_{z}$ is the steady-state growth rate.

Let $p_{t}$ be the nominal price level, $r_{t}$ the one-period nominal interest rate, $w_{t}$ the real wage, $b_{t}$ the flow value of unemployment (including unemployment benefits), $\Pi_{t}$ lump-sum profits, and $T_{t}$ lump-sum transfers. The household's budget constraint is then given by

$$
c_{t}+i_{t}+\frac{B_{t}}{p_{t} \varepsilon_{t}^{b} r_{t}}=w_{t} n_{t}+\left(1-n_{t}\right) b_{t}+r_{t}^{k} \nu_{t} k_{t-1}^{p}+\Pi_{t}+T_{t}-\mathcal{A}\left(\nu_{t}\right) k_{t-1}^{p}+\frac{B_{t-1}}{p_{t}},
$$

where $\varepsilon_{t}^{b}$ is a "risk premium" shock with mean $\varepsilon^{b}$ that drives a wedge between the risk-free interest rate set by the central bank and the return on assets held by the households. The first-order conditions with respect to $c_{t}, B_{t}, \nu_{t}, i_{t}$, and $k_{t}^{p}$ imply relationships that jointly determine consumption, capital utilization, the rental rate of capital, investment, and Tobin's $\mathrm{Q}$.

\footnotetext{
${ }^{8} \mathrm{As}$ in GST, we do not allow for variation in hours on the intensive margin. This choice is consistent with the observation that most of the cyclical variation in hours in the U.S. being on the extensive margin.
} 


\subsection{Unemployment, vacancies and matching}

There is a continuum of wholesale firms measured on the unit interval. To attract new workers wholesale firms need to post vacancies $v_{i t}$. The total number of vacancies and employed workers are then equal to $v_{t}=\int_{0}^{1} v_{i t} d i$ and $n_{t}=\int_{0}^{1} n_{i t} d i$. All unemployed workers are assumed to look for a job, and unemployed workers who find a match go to work immediately within the period. Accordingly, the pool of unemployed workers is given by

$$
u_{t}=1-n_{t-1} .
$$

The number of new hires is determined by the number of searchers and vacancies according to a matching function

$$
m_{t}=\varepsilon_{t}^{m} u_{t}^{\sigma} v_{t}^{1-\sigma}
$$

where $\varepsilon_{t}^{m}$ is a shock to the efficiency of the matching process with mean $\varepsilon^{m}$. The probability that a firm fills a vacancy is then given by $q_{t}=m_{t} / v_{t}$, and the probability that a worker finds a job is $s_{t}=m_{t} / u_{t}$. Both workers and firms take $q_{t}$ and $s_{t}$ as given.

\subsection{Wholesale firms}

Each wholesale firm $i$ produces output $y_{i t}$ using capital $k_{i t}$ and labor $n_{i t}$ according to the Cobb-Douglas production function

$$
y_{i t}=\left(k_{i t}\right)^{\alpha}\left(z_{t} n_{i t}\right)^{1-\alpha},
$$

where $z_{t}$ is a common labor-augmenting productivity factor, whose growth rate $\varepsilon_{t}^{z}=z_{t} / z_{t-1}$ follows a stationary exogenous process with steady-state value $\varepsilon^{z}$ which corresponds to the economy's steady-state (gross) growth rate $\gamma_{z}$. Thus, technology is non-stationary in levels but stationary in growth rates. We assume that capital is perfectly mobile across firms and that there is a competitive rental market for capital.

To hire new workers firms post vacancies $v_{i t}$. It is useful to define the hiring rate $x_{i t}$ as the ratio of new hires $q_{t} v_{i t}$ to the existing workforce $n_{i t-1}$ :

$$
x_{i t}=\frac{q_{t} v_{i t}}{n_{i t-1}}
$$

where the law of large numbers implies that the firm knows $x_{i t}$ with certainty at time $t$, as it knows the likelihood $q_{t}$ that each vacancy will be filled. Therefore, we can treat the hiring rate as the firm's control variable.

Firms exogenously separate from a fraction $1-\rho$ of their existing workforce $n_{i t-1}$ in each period, and workers who lose their jobs are not allowed to search until the next period. The total workforce is then the sum of the number of surviving workers and new hires:

$$
n_{i t}=\rho n_{i t-1}+x_{i t} n_{i t-1}
$$

which reflects the assumption that new hires go to work immediately. 
Let $p_{t}^{w}$ denote the relative price of intermediate goods, $w_{i t}^{n}$ the nominal wage and $\beta \mathrm{E}_{t} \Lambda_{t, t+1}$ be the firm's discount rate, where $\Lambda_{t, t+s}=\lambda_{t+s} / \lambda_{t}$ and $\lambda_{t}$ is the marginal utility of consumption at time $t$. Then the value of firm $i, F_{t}\left(w_{i t}^{n}, n_{i t-1}\right)$, is given by

$$
F_{t}\left(w_{i t}^{n}, n_{i t-1}\right)=p_{t}^{w} y_{i t}-\frac{w_{i t}^{n}}{p_{t}} n_{i t}-\frac{\kappa_{t}}{2} x_{i t}^{2} n_{i t-1}-r_{t}^{k} k_{i t}+\beta \mathrm{E}_{t}\left\{\Lambda_{t, t+1} F_{t+1}\left(w_{i t+1}^{n}, n_{i t}\right)\right\},
$$

where $\left(\kappa_{t} / 2\right) x_{i t}^{2} n_{i t-1}$ is a quadratic hiring cost with

$$
\kappa_{t}=\kappa z_{t} q_{t}^{-\eta_{q}}
$$

where $\eta_{q} \in[0,2]$ is a parameter denoting the elasticity of hiring costs to the vacancy filling rate $q_{t}$. As in GST, we allow hiring costs to drift proportionately with productivity $z_{t}$ in order to maintain a balanced steady-state growth path. We differ from GST by allowing for two types of hiring costs: search costs of recruiting new workers (advertising, screening, interviewing) and internal costs of adding new workers to a firm's labor force (such as training and other). Recruiting costs pertain to posted vacancies, $v_{i t}$, while training costs are associated with filled vacancies or new matches, $m_{i t}=q_{t} v_{i t}$. We will also refer to recruiting costs as prematch hiring costs, since they are incurred during the process of finding a new worker, and to training costs as post-match hiring costs, since they take place after the worker and the firm have matched and start an employment relationship. The combination of the two types of hiring costs is similar to formulations in Christiano, Trabandt, and Walentin (2011) and Furlanetto and Groshenny (2012b).

Our formulation encompasses both types of costs. If $\eta_{q}=0$, hiring costs are given by $\left(\kappa z_{t} / 2\right)\left(q_{t} v_{i t} / n_{i t-1}\right)^{2} n_{i t-1}$ and the cost function reduces to the one used in GST that emphasizes internal costs of adjusting employment. In this case, hiring costs have only to do with new hires and are not associated with the number of vacancies posted per se. For this reason, they are not affected by the likelihood $q_{t}$ that a vacancy is filled. If $\eta_{q}=2$, then hiring costs become $\left(\kappa z_{t} / 2\right)\left(v_{i t} / n_{i t-1}\right)^{2} n_{i t-1}$ and are only associated with posted vacancies. In this case, an increase in the aggregate likelihood $q_{t}$ with which each vacancy $v_{i t}$ is filled decreases the cost of hiring new workers. Because of the quadratic formulation, when only pre-match hiring costs are present the elasticity equals (minus) 2. For intermediate values of $\eta_{q}$, in between 0 and 2 , both costs are allowed for, with equal weight given to each cost when $\eta_{q}=1$.

The firm maximizes its value by choosing the hiring rate $x_{i t}$ and its capital stock $k_{i t}$, given its existing employment stock $n_{i t-1}$, the rental rate on capital $r_{t}^{k}$, the relative price of intermediate goods $p_{t}^{w}$, the likelihood of filling vacancies $q_{t}$, and the current and expected path of wages $w_{i t}^{n} / p_{t}$. The first-order condition for capital is given by

$$
r_{t}^{k}=p_{t}^{w} \alpha \frac{y_{i t}}{n_{i t}}=p_{t}^{w} \alpha \frac{y_{t}}{n_{t}}
$$

where all firms chose the same capital/output ratio due to Cobb-Douglas technology and perfect capital mobility. 
Firms choose $n_{i t}$ by setting $x_{i t}$. The optimal hiring decision yields

$$
\kappa_{t} x_{i t}=p_{t}^{w} a_{t}-\frac{w_{i t}^{n}}{p_{t}}+\beta \mathrm{E}_{t}\left\{\Lambda_{t, t+1} \frac{\kappa_{t+1}}{2} x_{i t+1}^{2}\right\}+\rho \beta \mathrm{E}_{t}\left\{\Lambda_{t, t+1} \kappa_{t+1} x_{i t+1}\right\}
$$

where

$$
a_{t}=(1-\alpha) \frac{y_{i t}}{n_{i t}}=(1-\alpha) \frac{y_{t}}{n_{t}}
$$

denotes the current marginal product of labor, which is also equal across firms. The hiring rate $x_{i t}$ thus depends on the discounted stream of earnings and the saving on adjustment costs. Observe that the only firm-specific variable affecting the hiring rate is the wage.

Finally, for the purpose of the wage bargain it is useful to define $J_{t}\left(w_{i t}^{n}\right)$, the value to the firm of having another worker at time $t$ after new workers have joined the firm, i.e., after adjustment costs are sunk. Differentiating $F_{t}\left(w_{i t}^{n}, n_{i t-1}\right)$ with respect to $n_{i t}$, taking $x_{i t}$ as given, and making use of the optimal hiring decision as well as the relation for the evolution of the workforce yields:

$$
J_{t}\left(w_{i t}^{n}\right)=p_{t}^{w} a_{t}-\frac{w_{i t}^{n}}{p_{t}}-\beta \mathrm{E}_{t}\left\{\Lambda_{t, t+1} \frac{\kappa_{t+1}}{2} x_{i t+1}^{2}\right\}+\left(\rho+x_{i t+1}\right) \beta \mathrm{E}_{t}\left\{\Lambda_{t, t+1} J_{t+1}\left(w_{i t+1}^{n}\right)\right\},
$$

where $J_{t}\left(w_{i t}^{n}\right)$ is expressed as expected average profits per worker net of first period adjustment costs, with the discount factor accounting for future changes in workforce size.

\subsection{Workers}

Let $V_{t}\left(w_{i t}^{n}\right)$ be the value to a worker of employment at firm $i$, and let $U_{t}$ be the value of unemployment. These values are defined after hiring decisions at time $t$ have been made and are measured in units of consumption goods. The value of employment is given by

$$
V_{t}\left(w_{i t}^{n}\right)=\frac{w_{i t}^{n}}{p_{t}}+\beta \mathrm{E}_{t}\left\{\Lambda_{t, t+1}\left[\rho V_{t+1}\left(w_{i t+1}^{n}\right)+(1-\rho) U_{t+1}\right]\right\}
$$

To construct the value of unemployment, denote by $V_{x, t}$ the average value of employment conditional on being a new worker, given by

$$
V_{x, t}=\int_{0}^{1}\left[V_{i t} \frac{x_{i t} n_{i t-1}}{x_{t} n_{t-1}}\right] d i
$$

Then, $U_{t}$ can be expressed as

$$
U_{t}=b_{t}+\beta \mathrm{E}_{t}\left\{\Lambda_{t, t+1}\left[s_{t+1} V_{x, t+1}+\left(1-s_{t+1}\right) U_{t+1}\right]\right\},
$$

where, as before, $s_{t}$ is the probability of finding a job, and

$$
b_{t}=b k_{t}^{p}
$$


is the flow value of unemployment (measured in units of consumption goods). The flow value is assumed to grow proportionately with the physical capital stock in order to maintain balanced growth.

Finally, the worker surplus at firm $i, H_{t}\left(w_{i t}^{n}\right)$, and the average worker surplus conditional on being a new hire, $H_{x, t}$, are given by

$$
\begin{aligned}
H_{t}\left(w_{i t}^{n}\right) & =V_{t}\left(w_{i t}^{n}\right)-U_{t}, \\
H_{x, t} & =V_{x, t}-U_{t} .
\end{aligned}
$$

It follows that

$$
H_{t}\left(w_{i t}^{n}\right)=\frac{w_{i t}^{n}}{p_{t}}-b_{t}+\beta \mathrm{E}_{t}\left\{\Lambda_{t, t+1}\left[\rho H_{t+1}\left(w_{i t+1}^{n}\right)-s_{t+1} H_{x, t+1}\right]\right\} .
$$

\subsection{Wage bargaining}

Firms and workers are not able to negotiate their wage contract in every period, but wage bargaining is assumed to be staggered over time, as in Gertler and Trigari (2009). As in Gertler, Sala, and Trigari (2008), firms and workers bargain over nominal wages. In each period, each firm faces a fixed probability $1-\lambda_{w}$ of being able to renegotiate the wage. The fraction $\lambda_{w}$ of firms that cannot renegotiate the wage instead index the nominal wage to past inflation according to

$$
w_{i t}^{n}=\bar{\gamma}_{w} \pi_{t-1}^{\gamma_{w}} w_{i t-1}^{n},
$$

where $\pi_{t}=p_{t} / p_{t-1}$ is the gross rate of inflation, $\bar{\gamma}_{w}=\gamma_{z} \pi^{1-\gamma_{w}}$, and $\gamma_{w} \in[0,1]$ measures the degree of indexing.

Let $w_{t}^{n *}$ denote the nominal wage of a firm-worker pair that renegotiates at $t$. Given constant returns to scale, all sets of renegotiating firms and workers set the same wage. The firm negotiates with the marginal worker over the surplus from the marginal match. Assuming Nash bargaining, the contract wage $w_{t}^{n *}$ is chosen to solve

$$
\max H_{t}\left(w_{i t}^{n}\right)^{\eta_{t}} J_{t}\left(w_{i t}^{n}\right)^{1-\eta_{t}}
$$

subject to

$$
w_{i t+j}^{n}= \begin{cases}\bar{\gamma}_{w} w_{i t+j-1}^{n} \pi_{t+j-1}^{\gamma_{w}} & \text { with probability } \lambda_{w} \\ w_{t+j}^{n *} & \text { with probability } 1-\lambda_{w}\end{cases}
$$

The variable $\eta_{t} \in[0,1]$ reflects the worker's relative bargaining power, and is assumed to evolve according to

$$
\eta_{t}=\eta \varepsilon_{t}^{\eta}
$$

where $\varepsilon_{t}^{\eta}$ is a shock with mean unity that implies a disturbance to the wage equation. 
The first-order condition for the Nash bargaining solution is given by

$$
\chi_{t}\left(w_{t}^{* n}\right) J_{t}\left(w_{t}^{* n}\right)=\left[1-\chi_{t}\left(w_{t}^{* n}\right)\right] H_{t}\left(w_{t}^{* n}\right),
$$

where

$$
\chi_{t}\left(w_{i t}^{n}\right)=\frac{\eta_{t}}{\eta_{t}+\left(1-\eta_{t}\right) \mu_{t}\left(w_{i t}^{n}\right) / \epsilon_{t}}
$$

is the (horizon-adjusted) effective bargaining power of workers,

$$
\mu_{t}\left(w_{i t}^{n}\right)=1+\beta \lambda_{w} \mathrm{E}_{t}\left\{\Lambda_{t, t+1}\left[\rho+x_{t+1}\left(\bar{\gamma}_{w} \pi_{t}^{\gamma_{w}} w_{i t}^{n}\right)\right] \frac{p_{t}}{p_{t+1}} \bar{\gamma}_{w} \pi_{t}^{\gamma_{w}} \mu_{t+1}\left(\bar{\gamma}_{w} \pi_{t}^{\gamma_{w}} w_{i t}^{n}\right)\right\}
$$

is the firm's cumulative discount factor, and

$$
\epsilon_{t}=1+\beta \rho \lambda_{w} \mathrm{E}_{t}\left\{\Lambda_{t, t+1} \frac{p_{t}}{p_{t+1}} \bar{\gamma}_{w} \pi_{t}^{\gamma_{w}} \epsilon_{t+1}\right\}
$$

is the worker's cumulative discount factor.

Finally, the average nominal wage is given by

$$
w_{t}^{n}=\int_{0}^{1}\left[w_{i t}^{n} \frac{n_{i t}}{n_{t}}\right] d i
$$

Given that the probability of wage adjustment is i.i.d., the law of large numbers implies that the evolution of the average nominal wage is a linear contract of the target nominal wage and last period's nominal wages of non-adjusters, after factoring in indexing arrangements:

$$
w_{t+1}^{n}=\left(1-\lambda_{w}\right) w_{t+1}^{* n}+\lambda_{w} \int_{0}^{1}\left(\bar{\gamma}_{w} \pi_{t}^{\gamma_{w}} w_{i t}^{n}\right) \frac{\rho+x_{t+1}\left(\bar{\gamma}_{w} \pi_{t}^{\gamma_{w}} w_{i t}^{n}\right) n_{i t}}{\rho+x_{t+1}\left(\bar{\gamma}_{w} \pi_{t}^{\gamma_{w}} w_{i t}^{n}\right) n_{t}} d i .
$$

\subsection{Retailers}

There is a continuum of monopolistically competitive retailers indexed by $j$ on the unit interval. These buy intermediate goods from the wholesale firms, differentiate them with a technology that transforms one unit of intermediate goods into one unit of retail goods, and sell them to households. Retailers set prices on a staggered basis.

Following Smets and Wouters (2007), we assume that each firm's elasticity depends inversely on its relative market share, as in Kimball (1995), who generalizes the standard Dixit-Stiglitz aggregator. Thus, letting $y_{j t}$ be the quantity of output sold by retailer $j$ and $p_{j t}$ the nominal price, final goods, denoted $y_{t}$, are a composite of individual retail goods following

$$
\int_{0}^{1} \mathcal{G}\left(\frac{y_{j t}}{y_{t}}, \varepsilon_{t}^{p}\right) d j=1
$$

where the function $\mathcal{G}(\cdot)$ is increasing and strictly concave with $\mathcal{G}(1)=1$, and $\varepsilon_{t}^{p}$ is a shock that influences the elasticity of demand.

We assume that prices are staggered as in Calvo (1983), but with indexing as in Christiano, 
Eichenbaum, and Evans (2005) and Smets and Wouters (2003). Thus, each retailer faces a fixed probability $1-\lambda_{p}$ of reoptimizing its price in a given period, in which case it sets its price to $p_{t}^{*}$ to maximize the expected discounted stream of future profits. All firms that reoptimize set the same price. Firms that do not reoptimize instead index their price to past inflation following

$$
p_{j t}=\bar{\gamma}_{p} \pi_{t-1}^{\gamma_{p}} p_{j t-1}
$$

where $\bar{\gamma}_{p}=\pi^{1-\gamma_{p}}$ is an adjustment for steady-state inflation.

It is possible to show that the optimal price $p_{t}^{*}$ depends on the expected discounted stream of the retailers' nominal marginal cost given by $p_{t} p_{t}^{w}$. Using the hiring condition (13), real marginal cost is given by

$$
p_{t}^{w}=\frac{1}{a_{t}}\left[\frac{w_{i t}}{p_{t}}+\kappa_{t} x_{i t}-\beta \mathrm{E}_{t}\left\{\Lambda_{t, t+1} \frac{\kappa_{t+1}}{2} x_{i t+1}^{2}\right\}-\rho \beta \mathrm{E}_{t}\left\{\Lambda_{t, t+1} \kappa_{t+1} x_{i t+1}\right\}\right],
$$

so real marginal cost depends on unit labor cost plus a term that corrects for the cost if hiring workers.

\subsection{The government sector}

The government sets government spending $g_{t}$ according to

$$
g_{t}=\left(1-\frac{1}{\varepsilon_{t}^{g}}\right) y_{t},
$$

where $\varepsilon_{t}^{g}$ follows an exogenous process. Our model neglects open-economy elements. The estimated process for $g_{t}$ therefore reflects the sum of government spending and net exports (and inventories). This choice is made for simplicity, but is potentially important when interpreting the recession in Sweden and Germany where external shocks were an important part of the recession.

The central bank sets the short-term nominal interest rate $r_{t}$ according to the Taylor rule

$$
\frac{r_{t}}{r}=\left(\frac{r_{t-1}}{r}\right)^{\rho_{s}}\left[\left(\frac{\mathrm{E}_{t} \pi_{t+1}}{\pi}\right)^{r_{\pi}}\left(\frac{y_{t}}{y_{t}^{n}}\right)^{r_{y}}\right]^{1-\rho_{s}} \varepsilon_{t}^{r},
$$

where $y_{t}^{n}$ is the level of output with flexible prices and wages and without shocks to the price markup and the bargaining power of workers, and $\varepsilon_{t}^{r}$ is a monetary policy shock.

\subsection{Resource constraint and model summary}

Finally, the resource constraint implies that output is equal to the sum of consumption, investment, government spending, and adjustment and utilization costs:

$$
y_{t}=c_{t}+i_{t}+g_{t}+\frac{\kappa_{t}}{2} \int_{0}^{1}\left[x_{i t}^{2} n_{i t-1}\right] d i+\mathcal{A}\left(\nu_{t}\right) k_{t-1}^{p} .
$$

The complete model consists of 28 equations for the 28 endogenous variables. There are 
also eight exogenous disturbances: to technology, investment, the risk premium, matching efficiency, the price markup, workers' bargaining power, government spending, and monetary policy. The technology shock follows a unit-root process, while the remaining seven shocks are stationary. In particular, technology growth and the other seven shocks follow

$$
\log \left(\varepsilon_{t}^{j}\right)=\left(1-\rho_{j}\right) \log \left(\varepsilon^{j}\right)+\rho_{j} \log \left(\varepsilon_{t-1}^{j}\right)+\zeta_{t}^{j},
$$

for $j=z, i, b, \sigma, p, \eta, g, r$, where $\varepsilon^{i}=\varepsilon^{b}=\varepsilon^{\sigma}=\varepsilon^{\eta}=\varepsilon^{r}=1$, and where $\zeta_{t}^{j}$ are mean-zero innovations with constant variances $\sigma_{j}^{2}$. We log-linearize the model around its deterministic steady state with balanced growth, allowing for the fact that output, investment, consumption, and the real wage are non-stationary. The derivation of the steady state and the log-linearized system of equations are available in the Appendix A.

\section{Estimation}

\subsection{Data and parameters}

We estimate the log-linearized version of the model on quarterly data from four countries: the U.S., the U.K., Sweden, and Germany. We estimate the model on data up to 2007Q1, before the start of the financial crisis, to prevent our estimates from being distorted by the non-linearities induced by the different size of the shocks and the zero lower bound on nominal interest rates. We then use the estimated model to interpret the period from 2007Q2 to 2011Q2. ${ }^{9}$ The first date of the sample period varies across countries. For the U.S., the data start in 1982Q1 (after the Volcker disinflation), for Germany in 1992Q1 (after the reunification), and for the U.K. and Sweden in 1994Q4 (after the introduction of inflation targeting regimes for monetary policy).

For each country we use data for eight variables: (1) output growth: the quarterly growth rate of per capita real GDP; (2) investment growth: the quarterly growth rate of a measure of per capita real investment; (3) consumption growth: the quarterly growth rate of a measure of per capita real consumption; (4) real wage growth: the quarterly growth rate of a measure of real compensation per hour; (5) inflation: the quarterly growth rate of the GDP deflator; (6) the nominal interest rate: the quarterly average of a short-term interest rate; (7) a measure of unemployment; and (8) a measure of vacancies. Data definitions and sources differ slightly across countries; they are available in Appendix B.

We estimate the model using Bayesian likelihood-based methods (see An and Schorfheide (2007) for an overview). Letting $\boldsymbol{\theta}$ denote the vector of structural parameters to be estimated and $\mathbf{Y}$ the data sample, we use the Kalman filter to calculate the likelihood $L(\boldsymbol{\theta}, \mathbf{Y})$, and then combine the likelihood function with a prior distribution of the parameters to be estimated, $p(\boldsymbol{\theta})$, to obtain the posterior distribution, $L(\boldsymbol{\theta}, \mathbf{Y}) p(\boldsymbol{\theta})$. We use numerical routines to maximize the value of the posterior, and then generate draws from the posterior distribution using the Random-Walk Metropolis-Hastings algorithm.

\footnotetext{
${ }^{9}$ Our empirical strategy thus follows Galí, Smets, and Wouters (2012) who also use a model estimated on pre-crisis data to interpret the Great Recession and the recovery in the U.S.
} 
We use growth rates for the non-stationary variables in our data set (output, consumption, investment, and the real wage, which are non-stationary also in the theoretical model) and express unemployment, vacancies, gross inflation and gross interest rates in percentage deviations from their sample mean. We write the measurement equation of the Kalman filter to match the eight observable series with their model counterparts. Thus, the state-space form of the model is characterized by the state equation

$$
\mathbf{X}_{t}=\mathbf{A}(\boldsymbol{\theta}) \mathbf{X}_{t-1}+\mathbf{B}(\boldsymbol{\theta}) \varepsilon_{t}, \quad \varepsilon_{t} \sim \text { i.i.d. } N\left(\mathbf{0}, \boldsymbol{\Sigma}_{\varepsilon}\right),
$$

where $\mathbf{X}_{t}$ is a vector of endogenous variables, $\varepsilon_{t}$ is a vector of innovations to the eight structural shocks, and $\boldsymbol{\theta}$ is a vector of parameters; and the measurement equation

$$
\mathbf{Y}_{t}=\mathbf{C}(\boldsymbol{\theta})+\mathbf{D X}_{t}+\boldsymbol{\eta}_{t}, \quad \boldsymbol{\eta}_{t} \sim \text { i.i.d. } N\left(\mathbf{0}, \boldsymbol{\Sigma}_{\eta}\right)
$$

where $\mathbf{Y}_{t}$ is a vector of observable variables, that is,

$$
\mathbf{Y}_{t}=100\left[\Delta \log Y_{t}, \Delta \log I_{t}, \Delta \log C_{t}, \Delta \log W_{t}, \log \pi_{t}, \log R_{t}, \log \left(u_{t} / \bar{u}\right), \log \left(v_{t} / \bar{v}\right)\right],
$$

and $\boldsymbol{\eta}_{t}$ is a vector of measurement errors.

The model contains twenty-two structural parameters, not including the parameters that characterize the exogenous shocks and measurement errors. We calibrate four parameters using standard values: the discount factor $\beta$ is set to 0.99 , the capital depreciation rate $\delta$ to 0.025 , the capital share $\alpha$ in the Cobb-Douglas production function is set to $1 / 3$, and the average ratio of government spending to output $G / Y$ is set to the average value for each country over the sample period. We also calibrate five other parameters. The steady-state growth rate, $\gamma_{z}$ is set to the average GDP growth rate over the sample period. The degree of indexation in price setting, $\gamma_{p}$ is set to zero. ${ }^{10}$ The match elasticity to unemployment, $\sigma$ in the matching function, is calibrated to 0.5 , a value within the range of empirical estimates, see Petrongolo and Pissarides (2001). Finally, the steady-state quarterly job survival and job finding probabilities $\rho$ and $s$, are computed from the yearly averages of monthly figures reported in Elsby, Hobijn, and Şahin (2012), following Justiniano and Michelacci (2012), but recalculated on our sample periods. These parameters indicate that labor markets are more or less sclerotic in the different countries. The U.S. is the most fluid labor market with high separation and job finding rates. Germany is at the other extreme. The U.K. and Sweden are similar also in this dimension, and are again intermediate cases between the U.S. and Germany. The calibrated parameters are shown in Table 1.

We estimate the remaining thirteen structural parameters. Of the thirteen, there are five parameters that are related to the labor market. These include: the steady-state bargaining power of workers $\eta$; the steady-state flow value of unemployment as a fraction of the contribution of the worker to the job, that is, the relative value of non-work to work activity, denoted with $\widetilde{b} ;{ }^{11}$ the weight on hiring costs, $\eta_{q}$; the wage rigidity parameter $\lambda_{w}$ and the

\footnotetext{
${ }^{10}$ When estimating the model without this restriction, $\gamma_{p}$ always ended up very close to zero for all countries, with no effect on other parameters.

${ }^{11}$ The relative flow value of unemployment is given by $\widetilde{b}=\bar{b} /\left[p^{w} \bar{a}+\beta(\bar{\kappa} / 2) x^{2}\right]$, where variables with no
} 
wage indexing parameter $\gamma_{w}$. The remaining eight parameters that we estimate include: the elasticity of the utilization rate to the rental rate of capital, $\eta_{\nu} ;{ }^{12}$ the elasticity of the investment adjustment cost function, $\eta_{k}$; the habit parameter $h$; the steady-state price markup $\varepsilon^{p}$; the price rigidity parameter $\lambda_{p}$; and the monetary policy rule parameters $r_{\pi}, r_{y}$, and $\rho_{s}$. In addition, we estimate the autoregressive parameters of the eight exogenous shock processes, as well as the standard deviations of the innovations. We allow for an i.i.d. measurement error on the real wage. This could be interpreted as proper errors in the measurement of wages, as in Justiniano, Primiceri, and Tambalotti (2012), or as volatility in the real wage that cannot be explained by our model, possibly due to model misspecification.

\subsection{Priors}

Before estimation we assign prior distributions to the parameters to be estimated. Most of the priors are standard in the literature; see, for example, Smets and Wouters (2007), Justiniano, Primiceri, and Tambalotti (2010) and, for the labor market parameters in particular, GST.

The utilization rate elasticity $\psi_{\nu}$ and the habit parameter $h$ are both assigned Beta priors with mean 0.5 and standard deviation 0.1 ; while the capital adjustment cost elasticity $\eta_{k}$ is assigned a Normal prior with mean 4 and standard deviation 1.5.

The Calvo parameter for price adjustment, $\lambda_{p}$, is assigned Beta prior with mean $2 / 3$ and standard deviation 0.1. The steady-state price markup $\varepsilon^{p}$ is assigned a Normal prior centered at 1.15 , with a standard deviation of 0.05 .

The coefficient $r_{\pi}$ on inflation in the monetary policy rule is given a Normal prior with mean 1.7 and standard deviation 0.3 , while the coefficient $r_{y}$ on output growth is given a Gamma prior with mean 0.125 and standard deviation 0.1. The coefficient on the lagged interest rate, $\rho_{s}$, is assigned a Beta prior with mean 0.75 and a standard deviation of 0.1 . All these are broadly consistent with empirically estimated monetary policy rules.

Of the five estimated labor market parameters, four are also estimated in GST and we assign the same priors as in GST. The steady-state bargaining power of workers $\eta$ and the relative flow value of unemployment $\widetilde{b}$ are both assigned a Beta prior with mean 0.5 and standard deviation 0.1. The Calvo parameter for wage adjustment, $\lambda_{w}$, is assigned Beta prior with means $3 / 4$ and standard deviation 0.1 , while the wage indexation parameter $\gamma_{w}$ is given a Uniform prior over the unit interval. The fifth labor market parameter, $\eta_{q}$, denoting the relative weight of recruiting costs in hiring, is new relative to GST and is assigned a Gamma distribution with mean 0.145 and standard deviation 0.1 . The prior mean has been specified following Silva and Toledo (2009) who estimate the relative importance of recruiting (pre-match) versus training (post-match) costs in the U.S. Their estimates correspond to $\eta_{q}=0.145$ in our framework. In the absence of evidence on the value of $\eta_{q}$ for the other countries, we will use the same prior for all of them.

All persistence parameters for the shocks are given Beta priors with mean 0.5 and standard deviation 0.1. Following much of the literature, we normalize some of the shocks be-

time index denote steady-state values of stationary variables and variables with a bar denote steady-state values of detrended variables.

${ }^{12}$ Following Smets and Wouters (2007), we define $\psi_{\nu}$ such that $\eta_{\nu}=\left(1-\psi_{\nu}\right) / \psi_{\nu}$ and estimate $\psi_{\nu}$. 
fore estimation, in order to better define a plausible range of variation. Three shocks - the investment-specific shock $\varepsilon_{t}^{i}$, the price markup shock $\varepsilon_{t}^{p}$, and the bargaining power shock $\varepsilon_{t}^{w}-$ are normalized to have a unitary contemporaneous impact on the physical capital stock, the real wage and price inflation, respectively. ${ }^{13}$ The priors assigned to the standard deviations of all innovations are Inverse Gamma, with mean 0.15 and standard deviation 0.15. The standard deviation of the measurement error on the real wage is assigned a Beta prior with mean and standard deviation equal, respectively, to $1 / 3$ and $1 / 10$ of the sample standard deviation of the real wage growth series.

All prior distributions are summarized in Tables 2 and 3.

\section{Results}

\subsection{Parameter estimates}

We begin by studying the estimated parameters. This will give an idea of structural differences across countries, in addition to the differences in the calibrated parameters. Tables 2-3 report the median and 5th and 95th percentiles of the estimated posterior distributions.

For the U.S., many parameter estimates are similar to those in the literature, e.g., Smets and Wouters (2007), Justiniano, Primiceri, and Tambalotti (2010), and Sala, Söderström, and Trigari (2010). Key labor market parameters, e.g., the steady-state bargaining power of workers, $\eta$, the flow value of unemployment, $\widetilde{b}$, and the degree of wage rigidity, $\lambda_{w}$, are very similar to the estimates in GST. Other parameters differ from GST, however. The estimated wage indexing parameter $\gamma_{w}$ is zero, compared with 0.8 in GST. At the same time, bargaining power shocks are quite persistent, $\rho_{\eta}=0.68$, more so than in GST, where $\rho_{\eta}=0.26$. Furthermore, the price markup shocks are not very persistent, $\rho_{p}=0.17$, compared with 0.8 in GST. ${ }^{14}$

Comparing parameter estimates across countries, the weight on pre-match hiring costs, $\eta_{q}$, is a key parameter for our analysis. Recall that $\eta_{q}=0$ indicates that only internal costs in new hires are present, $\eta_{q}=2$ indicates that all weight is assigned to search costs in posted vacancies, while $\eta_{q}=1$ indicates equal weights of the two costs. The parameter $\eta_{q}$ is estimated around 0.5 in the U.S., close to zero in the U.K. and Sweden, and close to one in Germany. The U.S. estimate is larger than the prior mean of 0.145 , which is adapted from Silva and Toledo (2009). Our estimate confirms their finding, as well as those of Yashiv (2000) and Furlanetto and Groshenny (2012b), that post-match training costs are quantitatively more important than pre-match recruiting costs in the U.S. This is true also in the U.K. and Sweden, similar to the results in Christiano, Trabandt, and Walentin (2011)

\footnotetext{
${ }^{13}$ To be more precise, as shown in Appendix A, the log-linearized Phillips curve is given by $\widehat{\pi}_{t}=\iota_{b} \widehat{\pi}_{t-1}+\iota_{o}\left(\widehat{p}_{t}^{w}+\widehat{\varepsilon}_{t}^{p}\right)+\iota_{f} \mathrm{E}_{t} \widehat{\pi}_{t+1}$,

where $\iota_{b}, \iota_{o}, \iota_{f}$ are convolutions of parameters. Instead of estimating the stochastic process for the price markup shock $\widehat{\varepsilon}_{t}^{p}$, we define the shock $\widetilde{\varepsilon}_{t}^{p} \equiv \iota_{o} \widehat{\varepsilon}_{t}^{p}$, and estimate the properties of $\widetilde{\varepsilon}_{t}^{p}$, which has a unitary contemporaneous impact on inflation. Similar normalizations are applied to the investment shock $\widehat{\varepsilon}_{t}^{i}$ and the bargaining power shock $\widehat{\varepsilon}_{t}^{w}$.

${ }^{14}$ These differences might be due to the different sample period relative to GST, but may also reflect weak identification between the persistence of shocks and the indexation parameters (see Canova and Sala (2009)).
} 
for Sweden.

Germany stands out with a large estimate for $\eta_{q}$, assigning approximately equal weights to recruiting and training costs. This is likely due to the shifts in the Beveridge curve in the estimation period. In Germany, unemployment was trending upwards until 2005, while vacancies were more cyclical. The Beveridge curve thus shifted outwards before 2005 (see Figure 3), which requires an important role for matching efficiency shocks, and therefore a relatively large $\eta_{q}$.

For the U.K. and Sweden there was no shift in the Beveridge curve during the (fairly short) estimation period (again, see Figure 3 ). This is likely the reason why $\eta_{q}$ is estimated close to zero. For these countries matching efficiency shocks will not be an important driver of unemployment dynamics. In the U.S., the Beveridge curve shifted inwards during the estimation period (see Daly, Hobijn, Şahin, and Valletta (2012)). This requires some role for matching efficiency shocks, and therefore a non-zero estimate for $\eta_{q}$, although the estimates still assign a larger role to post-match training costs.

The relative flow value of unemployment, $\widetilde{b}$, is larger in the U.K. and Sweden than in the U.S., which is consistent with the U.S. having a lower replacement rate than European countries. However, it is even smaller in Germany. This is possibly explained by the recent Hartz reforms in 2002-2006. A key feature of the reforms was to change the benefit system, reducing the level and the duration of unemployment benefit entitlements and conditioning them on active search behavior (see Burda and Hunt (2011) and Krause and Uhlig (2012)).

The steady-state bargaining power of workers, $\eta$, is large for all countries, in line with the results of GST.

A final parameter that stands out is the standard deviation of matching efficiency shocks, $\sigma_{m}$, which is considerably larger than the other standard deviations, and is particularly large in Germany. The large values are mainly due to the fact that we did not normalize this shock before estimation, in contrast to many other shocks. ${ }^{15}$

\subsection{Driving forces prior to the financial crisis}

Before studying how the model interprets the financial crisis and the Great Recession, we look at the driving forces of business cycles in the estimation period up until 2007Q1. Figures 4-7 present the time paths of the estimated shocks in the four countries (the vertical lines indicate the last observation in the sample used for estimation), and Table 4 shows a long-run variance decomposition of output growth, unemployment, and vacancies in the four countries.

In the U.S., most shocks are fairly stable during the estimation period, without any clear trend. The exception is the government spending shock, which shows a downward trend, consistent with the actual patterns in the ratios of government spending and net exports to GDP. Shocks to technology, investment, and the risk premium explain most of the variance in all variables. Matching efficiency shocks are only important for vacancies. They are not important drivers of business cycles since they do not generate a Beveridge curve, that is, they imply a positive co-movement between unemployment and vacancies. As in GST, shocks

\footnotetext{
${ }^{15}$ In particular, we could have normalized it to have a unitary effect on employment. This would have reduced the standard deviation of the shock leaving everything else basically unchanged.
} 
to the price markup, workers' bargaining power, government spending, and monetary policy are not important driving forces of business cycle fluctuations.

In the U.K. the estimated shocks and the variance decomposition are similar to the U.S. The main exception is that shocks to government spending (and net exports) have a larger impact on output and vacancies compared with the U.S., and also monetary policy shocks are more important. As in the U.S., bargaining power shocks and price markup shocks do not contribute at all to business cycle fluctuations, while matching efficiency shocks are important only for vacancies.

For Sweden, there is a slight upward trend in the estimated risk premium shock and a downward trend in government spending and net exports, reflecting the off-setting effects of a fiscal consolidation since the mid-1990s and a build-up of a current account surplus. The variance decomposition is similar to the U.K., with a more important role of government spending and net exports as well as monetary policy than in the U.S.

In Germany, there are upward trends in both the risk premium and government spending and net exports, reflecting the strong external position of Germany. There is substantial variation also in the bargaining power shock, which falls until 2000, then increases until around 2004 and finally falls back again. The matching efficiency shock is characterized by a series of negative realizations during the estimation period.

To understand the role of labor market shocks, it is important to recall that Germany experienced significant trends in unemployment, which increased after reunification from 1992 to 2005 (basically during our estimation period) and decreased after that (during our evaluation period). In contrast, vacancies do not display any trend and only display cyclical behavior. The increasing trend in unemployment during the estimation period is largely attributed to matching efficiency shocks. The matching efficiency shocks (together with an important role for pre-match recruiting costs) are required to explain the outward shift of the German Beveridge curve from 1994 to 2005. On the other hand, cyclical fluctuations in both unemployment and vacancies are due to both matching efficiency shocks and bargaining power shocks. Indeed those two shocks explain together 92 percent of the variance in unemployment, while bargaining power shocks explain 53 percent of the variation in vacancies. Another factor that may explain why those shocks that are important to explain the variance in output only play a minor role in explaining unemployment is the structure of the labor market, particularly the fact that the German labor market is highly sclerotic, that is, it displays low job finding and separation rates (see also the discussion of the counterfactuals below). Intuitively, shocks that do not affect labor markets directly do not propagate much in sclerotic labor markets.

The variance decomposition of output in Germany is not very different from the other three countries.

Summing up, the main differences between Germany and the other countries lie in the labor market. While in the U.S., U.K., and Sweden the same shocks (to technology, government spending, investment, and the risk premium) explain the bulk of variation in both GDP and labor market variables (unemployment and vacancies), in Germany output is explained with the same shocks as for the other three countries, while unemployment and vacancies are mostly explained by the labor market shocks. 


\subsection{What happened during the financial crisis?}

We now focus on how our estimated models interpret the period after 2007Q1. For this purpose we compare the estimated time paths of the shocks in Figures 4-7 before and after 2007, and we present decompositions of output growth, unemployment, vacancies, and wages from 2007Q1 until mid-2011. Finally, we decompose movements in the Okun's law relationship and the Beveridge curve.

\subsubsection{Driving forces after 2007}

In the U.S., the period after 2007 is characterized by a large increase in the risk premium shock (capturing the effects of financial frictions) and a large drop in matching efficiency. Since 2008 there is also an increase in the monetary policy shock, as the zero-lower bound on the nominal interest rate becomes binding, and the interest rate is set at a level higher than that implied by the monetary policy rule.

The technology shock increases gradually in the aftermath of the financial crisis capturing an increase in productivity associated with the slow recovery in unemployment relatively to output. The shock to workers' bargaining power (that is, to wage setting) rises moderately in the recession, reflecting the fact that wage growth did not slow down as much as implied by the severity of the recession. In contrast, the shocks to investment and the price markup are fairly stable throughout.

In the U.K., the period following the financial crisis is characterized by negative technology shocks, an increased risk premium, reduced wage pressure (a low bargaining power shock), and reduced matching efficiency. To counter the effects of the crisis, monetary policy was more expansionary after 2007 than implied by the estimated policy rule, so the zero-lower bound did not seem to be binding. Comparing with the U.S., we note the opposite patterns for the technology shock, the monetary policy shock, and the bargaining power shock. As in the U.S. matching efficiency initially decreased, but while in the U.S it remained at low levels, in the U.K. it returned to more normal levels.

In Sweden and Germany the estimated shocks are largely similar to those in the U.K. One exception is the risk premium shock, which does not increase as much in Sweden and Germany during the financial crisis, and in particular in Germany there are no signs of increased financial frictions after 2007. As in the U.K., the zero-lower bound did not seem to be binding in Sweden and Germany. Matching efficiency fell also in Sweden in 2007, and remained at low levels until 2011. This helps to account for the outward shift in the Swedish Beveridge curve. For Germany, in contrast, we see that the matching efficiency shock trends up mildly in the Great Recession period, consistently with the decreasing trend in unemployment starting from 2005. As we previously discussed, in Germany changes in matching efficiency capture movements in the Beveridge Curve associated with trends in unemployment.

In all countries, the shock to government spending and net exports follow closely movements in the ratio of government spending and net exports to GDP. At the time of the crisis or slightly later there was an increase in government spending relative to GDP in all countries. In the U.S. there was also an increase in net exports relative to GDP, while in the 
other three countries there was a significant decrease in net exports relative to GDP. Thus, the combined effect of government spending and net exports is positive in the U.S., but it is reversed quickly due to a contraction in government spending from 2009 onwards. In the U.K. and Sweden, the increase in government spending dominates the fall in net exports relative to GDP. In Germany the two effects basically offset each other.

\subsubsection{Explaining the contraction in output}

Figure 8 shows the contribution of different shocks to GDP from 2007 until 2011. (The figure shows cumulated GDP growth since 2007Q1.) The patterns are quite different in the U.S. relative to the European countries.

In the U.S. the fall in GDP during 2008 and 2009 is mainly explained by the risk premium shock. A similar pattern is visible for the U.K., although to a lesser extent, but it is virtually absent in Sweden and Germany. One interpretation is that this shock reflects the reduction in both consumption and investment driven by increases in financial frictions affecting both households and firms.

The risk premium shock in our model is a short-cut to model financial frictions, following Smets and Wouters (2007). More careful modeling of financial frictions motivate similar shocks as due to moral hazard and asymmetric information in the firm sector (e.g., Bernanke, Gertler, and Gilchrist (1999)) or tightened credit constraints due to an increase in the perception of risk of household debt (as in Guerrieri and Lorenzoni (2011)). A positive risk premium shock increases the wedge between the cost of borrowing and its benefit to the household as well as the wedge between the cost of borrowing and the return to capital to the firm. Thus it reduces consumption and investment. Other papers consider either wedge in isolation, whereas our model captures both wedges, although in a reduced-form manner where the wedges are exogenous and cannot be separately identified. Hall (2012), in contrast, considers both wedges and can separately identify them.

There is a striking difference between the U.S. and the other three countries in the role of technology shocks. These shocks explain all of the decrease in output in Sweden, most of it in the U.K. (even though the risk premium is also important), and part of the decline in output in Germany, but they contribute to keeping output high in the U.S. To a large extent, the negative impact of technology shocks in the European countries may capture the reduction in output per worker due to labor hoarding associated, in turn, with a reduction in hours per worker and, possibly, with a temporary reallocation of workers from productive to organizational activities. While the U.S. experienced almost no change in hours per worker, so that almost the entire decrease in total hours was due to a decrease in employment, in the U.K. the decrease in total hours was associated with changes in employment and hours per worker of similar magnitude. In Sweden, hours per worker remained fairly stable after 2007, implying that most of the decrease in total hours was due to a decrease in employment. Germany again differs from the other countries, as hours per worker fell more than total hours and employment therefore increased. The reduction in hours per worker in Germany was due to the use of both government-sponsored short-time work and working time accounts ${ }^{16}$, in

\footnotetext{
${ }^{16}$ The personnel management practice of working time accounts allows employers to raise hours above
} 
addition to a reduction in standard weekly hours and overtime.

Government spending and net exports contribute positively to output in all countries, although the effects are short-lived in the U.S., where the increase was quickly reversed (see Figure 4). As noted earlier, the zero lower bound seems to be binding only for the U.S., where monetary policy is contractionary. For the three other countries monetary policy contributes to keeping output high.

Finally, the labor market shocks (to the bargaining power and matching efficiency) have some effects on output. In particular, reduced matching efficiency in the U.S. contributes to lower output starting in the second half of 2008. In general, however, the labor market shocks are relatively more important for the labor market variables to which we turn next.

\subsubsection{Unemployment}

The role of financial shocks for the U.S. is even more clear when explaining the increase in unemployment, see Figure 9. From the end of 2008 the risk premium shock increases the unemployment rate by more than two percentage points. Reduced matching efficiency explains another percentage point of the increase in unemployment. These effects are quite persistent, helping to explain why unemployment stayed high through 2011. Shocks to investment are also important for the increase in unemployment.

Wage setting shocks (to workers' bargaining power) are small and therefore have a modest impact on unemployment. This is in stark contrast to Galí, Smets, and Wouters (2012), where similar wage setting shocks (to the wage markup) are the dominant explanation for the increase in unemployment since 2008. In our model, this role seems to be taken over by shocks to the matching process, an explanation that has also featured prominently in the policy debate (see, for instance, Kocherlakota (2010)). At the same time, the fact that bargaining power shocks are not large indicates that in this model there are not large tensions between the dynamics of wages and employment.

Monetary policy shocks and investment shocks also contribute to high unemployment in the U.S., while technology shocks have a more muted impact on unemployment compared with output.

These results are broadly consistent with Furlanetto and Groshenny (2012b), who also find that shocks to the risk premium, investment, and matching efficiency are important to explain the increase in unemployment in the U.S.

The estimated changes in matching efficiency in the U.S. may of course capture a number of factors that are not present in our model. For instance, skill or geographical mismatch (as discussed by Şahin, Song, Topa, and Violante (2011) and Sterk (2011)), a reduction in the recruiting intensity with which firms try to fill posted vacancies (see Davis, Faberman, and Haltiwanger (2012)), a reduction in the search intensity of unemployed workers, due to the extended unemployment benefit programs (see Kuang and Valletta (2010)), or changes in the composition of the unemployment pool or in demographics (see Barnichon and Figura (2011, 2012)). Finally, matching efficiency shocks could capture an increase in separations

standard hours with no immediate payment, as long as hours are reduced in compensation over a time window in the future with no correspondent cut in pay (see Burda and Hunt (2011)). 
during the early part of the financial crisis, which is not allowed for in our model where the separation rate is constant.

In the U.K. the increase in unemployment is largely due to the risk premium shock and technology shocks, but also shocks to government spending and net exports contribute to keeping unemployment high, despite the fact that these factors also tended to increase output. The increase in unemployment is moderated by expansionary monetary policy and shocks to investment-specific technology. Further analysis (not reported here) shows that the investment shock mainly explains the low-frequency component of unemployment, rather than the cyclical component. We find similar patterns for Sweden as in the U.K. In both Sweden and the U.K., matching efficiency shocks have a small impact on unemployment, as post-match training costs are more important than pre-match recruiting costs. As we will see below, matching efficiency shocks in these countries have a larger effect on vacancies than on unemployment.

The unemployment decomposition in Germany follows a very different pattern than in the other countries. According to our model, the persistent reduction in unemployment in Germany during the evaluation period is largely explained by labor market shocks: improved matching efficiency and reduced bargaining power of workers. These shocks potentially capture three important aspects of the German labor market since 2000. First, the labor market reforms undertaken in the first half of the 2000, which reduced the duration of unemployment benefits and made requirements for benefits stricter (see Burda and Hunt (2011) or Krause and Uhlig (2012)), and increased the efficiency of job search by introducing stricter sanctions for refusing job offers (see Fahr and Sunde (2009)). Second, the increased use of short-time work and working time reductions to adjust the labor input at the intensive margin. Third, the delayed effect of the wage moderation that characterized the German labor market between 2000 and 2008, a consequence of the reduced power of labor unions.

\subsubsection{Vacancies}

For vacancies in Figure 10, financial shocks lead to a reduction in vacancies in the U.S., while the reduced efficiency of the matching process has a positive impact on vacancies since early 2008. Matching efficiency shocks thus contribute to keep vacancies high, while at the same time keeping output growth low and unemployment high.

Matching efficiency shock also play a similar role in the U.K. and Sweden. There is almost no effect of matching efficiency shocks on vacancies in Germany, as pre-match recruiting costs are more important. Instead, bargaining power shocks have a strong positive impact on vacancies in Germany.

The outward shift in the U.S. Beveridge curve is explained by negative matching efficiency shocks that keep vacancies high relative to unemployment. The shift inward of the German Beveridge curve is instead explained by positive matching efficiency shocks that keep unemployment down relative to vacancies. This is due to the relatively low value of the elasticity of hiring costs to the job filling probability, $\eta_{q}$, in the U.S. and to its relatively high value in Germany. 


\subsubsection{Wages}

Finally, Figure 11 shows the decomposition of the real wage since 2007. (The figures show the cumulated change in the real wage since 2007Q1.) For the real wage we also add the effects of measurement errors. Thus, we report both the actual level of wages and the model-implied level of wages, net of the measurement error (the dashed lines).

For the U.S., risk premium and investment shocks reduce wages. In contrast, the bargaining power shock has a large positive impact on wages. This could be interpreted as (downward) wage rigidity in addition to that delivered by the model and needed to explain why wages have not fallen as much as implied by the high level of unemployment. An alternative and more direct interpretation of the bargaining power shock is that it captures firm deleveraging that placed workers in a more favorable position in wage bargaining, as proposed by Monacelli, Quadrini, and Trigari (2011).

Bargaining power shocks have a negative impact on wages in Germany, consistent with the wage moderation interpretation mentioned when discussing unemployment.

For the U.K. and Sweden, labor market shocks are not very important for real wages. Instead, technology shocks have a negative impact on wages while investment shocks, price markup shocks and monetary policy shocks have a positive impact.

The measurement errors are sizable in the U.S. and Germany, but more modest in the U.K. and Sweden. We obtain a negative measurement error on wages in the U.S. and a positive error in Germany. While this is hard to reconcile with the effect of the bargaining power shock, one interpretation is that this captures the moderate growth of wages relative to productivity in the U.S. and the excessive growth of wages relative to productivity in Germany.

\subsubsection{Okun's law}

Figures 12-15 show decompositions of the Okun's law relationship in the four countries, that is relationships conditional on one shock at a time. As in Figure 2, the blue sections correspond to the period from 1995 to 2006 and the green sections to 2007-2011.

In the U.S., the large movements towards the north-west are mainly due to risk premium shocks, that increased unemployment and reduced GDP growth. It is however not obvious which combination of shocks caused the steepening of the relationship after 2007.

For the U.K., risk premium shocks were also important to increase unemployment and reduce GDP growth, but the flattening of the Okun's law relationship seems entirely due to technology shocks, that reduced GDP growth but had a smaller impact on unemployment. The same pattern is visible in Sweden.

In Germany, finally, the Okun's law relationship is essentially flat since 2007, and seems largely due to shocks to technology and investment that have reduced GDP growth with no impact on unemployment. These shocks do not transmit to unemployment mainly because the German labor market is highly sclerotic, that is, it is characterized by relatively low job finding and job separation probabilities. Matching efficiency shocks do not create any clear pattern in the Okun's law relationship. 


\subsubsection{The Beveridge curve}

Figures 16-19 show similar decompositions of the Beveridge curve.

For the U.S., the figure confirms that the outward shift in the Beveridge curve since 2009 was driven by shocks to the matching efficiency which generate a positive comovement between unemployment and vacancies. All other shocks instead move the economy along a stable Beveridge Curve. As noted earlier, monetary shocks and risk premium shocks were unusually large during the Great Recession compared with the period before 2007.

Most shocks generate movements with typical counter-clockwise loops in the unemploymentvacancies space that are due to the different dynamics and timing of unemployment and vacancies: in recessionary phases and subsequent recoveries, vacancies tend to move first, with unemployment reacting with a lag. As in the unconditional Beveridge curve, some of the shocks have not concluded the movement along the loop.

For the U.K., we do not observe any shifts in the Beveridge curve after 2007, but movements along the curve were unusually large after 2007. This is mainly generated by shocks to technology and the risk premium, which both tended to increase unemployment and reduce vacancies.

The shift in the Swedish Beveridge curve is mainly due to an increase in vacancies for a given level of unemployment. The decomposition shows that this is largely due to matching efficiency shocks, which have a large impact on vacancies but little on unemployment.

And for Germany, shocks to the matching efficiency and the bargaining power are the only ones to have an impact on the Beveridge curve. Improved matching efficiency have tended to reduce unemployment for a given level of vacancies, shifting the Beveridge curve inwards, while bargaining power shocks have led to large movements along the Beveridge curve.

\subsection{Counterfactual experiments}

Some of the structural shocks, in particular shocks to technology and matching efficiency, may be capturing missing factors in the model. This caveat notwithstanding, under the assumption that the model and the shocks are truly structural, we can run counterfactual experiments to answer questions such as: What would unemployment in Germany have been if the labor market structure had been more similar to that in the U.S.?

The first column of Figure 20 plots actual unemployment and output in Germany since 2007 together with counterfactual unemployment and output when we set all labor market parameters - specifically $\eta, \sigma, \rho, s, \widetilde{b}, \eta_{q}, \lambda_{w}$, and $\gamma_{w}$ - to the U.S. values, keeping everything else unchanged. In particular, we keep the estimated shocks series for Germany. The figure shows that while output would have displayed similar dynamics in Germany if the labor market structure had been similar to that in the U.S., the unemployment rate would have behaved very differently: unemployment would have increased substantially in Germany during the Great Recession, more in line with the U.S. experience. These effects are largely explained by the U.S. labor market being less sclerotic than the German labor market. The second column of Figure 20 plots, together with German output and unemployment, the counterfactual output and unemployment when we only change the average job finding rate, $s$, and the average job separation rate, $1-\rho$, to the U.S. values. The figures show that a less 
sclerotic labor market in the counterfactual experiment for Germany - a higher $s$ and a lower $\rho$-is responsible for almost all of the effect displayed in the first column. It is important to note, however, that if the German labor market had been more similar to that in the U.S., then it would have entered the Great Recession with a higher unemployment rate than in the U.S. Less sclerotic labor markets may deliver better labor market outcomes in good times, but insulates the labor markets from the adverse effects of large recessionary episodes or crises.

\section{Conclusions and final remarks}

In this paper we try to shed light on why different industrialized economies have had very different labor market experiences during the Great Recession and the subsequent recovery. To this purpose, we estimate a version of the model developed by Gertler, Sala, and Trigari (2008) to study labor market dynamics in four different countries: the U.S., the U.K., Sweden, and Germany. We focus on the relative importance of structural and cyclical forces in determining economic outcomes. We find that while different shocks explain the recession and the labor market experience in the four countries, structural differences in the labor market also played a role.

Our study comes with a number of caveats. Using a unified framework for all countries simplifies comparison across countries. The disadvantage is that this framework is unable to capture all country-specific factors and labor market institutions that were important in determining labor market outcomes. An important area for future research is to better adapt the model to such factors. This is particularly true for Germany where a number of institutional changes and reforms have taken place in the labor market since reunification.

Accordingly, the model and our approach can be extended in a number of directions. In general, it would be useful to extend the model to include an intensive margin, endogenous separation, and an external sector, as in Christiano, Trabandt, and Walentin (2011). Another useful extension would be to develop further the labor market specification to look into the microfoundations of time-varying matching efficiency. It would also be desirable to use additional data on flows as in Justiniano and Michelacci (2012) and, more generally, to spend more resources on data collection.

Finally, we plan to further investigate the different role played by wage markup shocks in Galí, Smets, and Wouters (2012) and bargaining power shocks in Gertler, Sala, and Trigari (2008) and study the consequences of these differences for natural and potential output along the lines of Sala, Söderström, and Trigari (2010). 


\section{A Model appendix}

\section{A.1 Steady state calculation}

Let $\bar{y}$ denote $y_{t} / z_{t}$ evaluated at steady state for any variable $y_{t}$.

- Consumption and savings

$$
1=\varepsilon^{b} r\left(\beta / \gamma_{z}\right)
$$

- Physical capital

$$
1=\left(\beta / \gamma_{z}\right)\left(1-\delta+r^{k}\right)
$$

- Capital/employment ratio

$$
r^{k}=\alpha p^{w}(\bar{k} / n)^{-(1-\alpha)}
$$

- Marginal product of labor

$$
\bar{a}=(1-\alpha)(\bar{k} / n)^{\alpha}
$$

- Investment

$$
q^{k}=1
$$

- Rates

$$
x=1-\rho
$$

- Flows

$$
x n=s u
$$

- Unemployment

$$
u=1-n
$$

- Matching

$$
s u=\varepsilon^{\sigma} u^{\sigma} v^{1-\sigma}
$$

- Hiring

$$
\bar{\kappa} x=p^{w} \bar{a}-\bar{w}+\beta \frac{\bar{\kappa}}{2} x^{2}+\beta \rho \bar{\kappa} x
$$


- Wages

$$
\bar{w}=\chi\left(p^{w} \bar{a}+\beta \frac{\bar{\kappa}}{2} x^{2}+\beta \bar{\kappa} s x\right)+(1-\chi) \bar{b}
$$

where

$$
\chi=\frac{\eta}{\eta+(1-\eta) \mu / \epsilon}, \quad \mu=\frac{1}{1-\lambda \beta}, \quad \epsilon=\frac{1}{1-\rho \lambda \beta}
$$

- Hiring and vacancy costs

$$
\bar{\kappa}=\kappa q^{-\eta_{q}}
$$

- Resource constraint

$$
1=\frac{\bar{c}}{\bar{y}}+\frac{\bar{g}}{\bar{y}}+\frac{\bar{\imath}}{\bar{y}}+\frac{\bar{\kappa}}{2} x^{2} \frac{n}{\bar{y}}
$$

where

$$
n / \bar{y}=(\bar{k} / n)^{-\alpha} \quad \bar{\imath} / \bar{y}=\left(1-\frac{1-\delta}{\gamma_{z}}\right) \gamma_{z}(\bar{k} / n)^{(1-\alpha)}
$$

\section{A.2 Log-linear model}

- Technology

$$
\widehat{y}_{t}=\alpha \widehat{k}_{t}+(1-\alpha) \widehat{n}_{t}
$$

- Resource constraint

$$
\widehat{y}_{t}=y_{c} \widehat{c}_{t}+y_{i} \widehat{i}_{t}+y_{g} \widehat{g}_{t}+y_{\nu} \widehat{\nu}_{t}+y_{x}\left(\widehat{\kappa}_{t}+2 \widehat{x}_{t}+\widehat{n}_{t-1}\right)
$$

where

$$
y_{c}=\bar{c} / \bar{y}, \quad y_{i}=\bar{\imath} / \bar{y}, \quad y_{g}=\bar{g} / \bar{y}, \quad y_{\nu}=r^{k} \bar{k} / \bar{y}, \quad y_{x}=(\bar{\kappa} / 2)\left(x^{2} n / \bar{y}\right)
$$

- Matching

$$
\widehat{m}_{t}=\widehat{\varepsilon}_{t}^{\sigma}+\sigma \widehat{u}_{t}+(1-\sigma) \widehat{v}_{t}
$$

- Employment dynamics

$$
\widehat{n}_{t}=\widehat{n}_{t-1}+(1-\rho) \widehat{x}_{t}
$$


- Transition probabilities

$$
\begin{aligned}
& \widehat{q}_{t}=\widehat{m}_{t}-\widehat{v}_{t} \\
& \widehat{s}_{t}=\widehat{m}_{t}-\widehat{u}_{t}
\end{aligned}
$$

- Unemployment

$$
\widehat{u}_{t}=-(n / u) \widehat{n}_{t-1}
$$

- Effective capital

$$
\widehat{k}_{t}+\widehat{\varepsilon}_{t}^{z}=\widehat{\nu}_{t}+\widehat{k}_{t-1}^{p}
$$

- Physical capital dynamics

$$
\widehat{k}_{t}^{p}=\xi\left(\widehat{k}_{t-1}^{p}-\widehat{\varepsilon}_{t}^{z}\right)+(1-\xi)\left(\widehat{i}_{t}+\widehat{\varepsilon}_{t}^{i}\right)
$$

where

$$
\xi=\frac{1-\delta}{\gamma_{z}}
$$

- Aggregate vacancies

$$
\widehat{x}_{t}=\widehat{q}_{t}+\widehat{v}_{t}-\widehat{n}_{t-1}
$$

- Consumption and saving

$$
0=\mathrm{E}_{t} \widehat{\Lambda}_{t, t+1}+\left(\widehat{\varepsilon}_{t}^{b}+\widehat{r}_{t}-\mathrm{E}_{t} \widehat{\pi}_{t+1}\right)-\mathrm{E}_{t} \widehat{\varepsilon}_{t+1}^{z}
$$

- Marginal utility

$$
(1-\widetilde{h})(1-\beta \widetilde{h}) \widehat{\lambda}_{t}=\widetilde{h}\left(\widehat{c}_{t-1}-\widehat{\varepsilon}_{t}^{z}\right)-\left(1+\beta \widetilde{h}^{2}\right) \widehat{c}_{t}+\beta \widetilde{h} \mathrm{E}_{t}\left(\widehat{c}_{t+1}+\widehat{\varepsilon}_{t+1}^{z}\right)
$$

where

$$
\widetilde{h}=h / \gamma_{z}
$$

- Capital utilization

$$
\widehat{\nu}_{t}=\eta_{\nu} \widehat{r}_{t}^{k}
$$

where

$$
\eta_{\nu}=\mathcal{A}^{\prime}(1) / \mathcal{A}^{\prime \prime}(1)=\frac{1-\psi_{\nu}}{\psi_{\nu}}
$$


- Investment

$$
\widehat{i}_{t}=\frac{1}{1+\beta}\left(\widehat{i}_{t-1}-\widehat{\varepsilon}_{t}^{z}\right)+\frac{1 /\left(\eta_{k} \gamma_{z}^{2}\right)}{1+\beta}\left(\widehat{q}_{t}^{k}+\widehat{\varepsilon}_{t}^{i}\right)+\frac{\beta}{1+\beta} \mathrm{E}_{t}\left(\widehat{i}_{t+1}+\widehat{\varepsilon}_{t+1}^{z}\right)
$$

where

$$
\eta_{k}=\mathcal{S}^{\prime \prime}\left(\gamma_{z}\right)
$$

- Capital renting

$$
\widehat{p}_{t}^{w}+\widehat{y}_{t}-\widehat{k}_{t}=\widehat{r}_{t}^{k}
$$

- Tobin's q

$$
\widehat{q}_{t}^{k}=\widetilde{\beta}(1-\delta) \mathrm{E}_{t} \widehat{q}_{t+1}^{k}+[1-\widetilde{\beta}(1-\delta)] \mathrm{E}_{t} \widehat{r}_{t+1}^{k}-\left(\widehat{\varepsilon}_{t}^{b}+\widehat{r}_{t}-\mathrm{E}_{t} \widehat{\pi}_{t+1}\right)
$$

where

$$
\widetilde{\beta}=\beta / \gamma_{z}
$$

- Aggregate hiring rate

$$
\left(\widehat{\kappa}_{t}+\widehat{x}_{t}\right)=\varkappa_{a}\left(\widehat{p}_{t}^{w}+\widehat{a}_{t}\right)-\varkappa_{w} \widehat{w}_{t}+\varkappa_{\lambda} \mathrm{E}_{t} \widehat{\Lambda}_{t, t+1}+\beta \mathrm{E}_{t}\left(\widehat{\kappa}_{t+1}+\widehat{x}_{t+1}\right)
$$

where

$$
\varkappa=(\bar{\kappa} x)^{-1}, \quad \varkappa_{a}=\varkappa p^{w} \bar{a}, \quad \varkappa_{w}=\varkappa \bar{w}, \quad \varkappa_{\lambda}=\beta(1+\rho) / 2
$$

- Hiring-vacancy cost

$$
\widehat{\kappa}_{t}=-\eta_{q} \widehat{q}_{t}
$$

where

$$
\eta_{q}=\frac{2 \varphi / \bar{q}}{\varphi / \bar{q}+(1-\varphi)}
$$

- Marginal product of labor

$$
\widehat{a}_{t}=\widehat{y}_{t}-\widehat{n}_{t}
$$

- Weight in Nash bargaining

$$
\widehat{\chi}_{t}=-(1-\chi)\left(\widehat{\mu}_{t}-\widehat{\epsilon}_{t}\right)
$$


with

$$
\begin{aligned}
\widehat{\epsilon}_{t}= & (\rho \lambda \beta) \mathrm{E}_{t}\left(\widehat{\Lambda}_{t, t+1}-\widehat{\pi}_{t+1}+\gamma \widehat{\pi}_{t}+\widehat{\epsilon}_{t+1}-\widehat{\varepsilon}_{t+1}^{z}\right) \\
\widehat{\mu}_{t}= & (x \lambda \beta) \mathrm{E}_{t} \widehat{x}_{t+1}-(x \lambda \beta)\left(\varkappa_{w} \mu\right) \mu \mathrm{E}_{t}\left(\widehat{w}_{t}+\gamma \widehat{\pi}_{t}-\widehat{\pi}_{t+1}-\widehat{\varepsilon}_{t+1}^{z}-\widehat{w}_{t+1}\right) \\
& +(\lambda \beta) \mathrm{E}_{t}\left(\widehat{\mu}_{t+1}+\widehat{\Lambda}_{t, t+1}+\gamma \widehat{\pi}_{t}-\widehat{\pi}_{t+1}-\widehat{\varepsilon}_{t+1}^{z}\right)
\end{aligned}
$$

- Spillover-free target wage

$$
\begin{aligned}
\widehat{w}_{t}^{o}= & \varphi_{a}\left(\widehat{p}_{t}^{w}+\widehat{a}_{t}\right)+\left(\varphi_{s}+\varphi_{x}\right) \mathrm{E}_{t} \widehat{x}_{t+1}+\varphi_{s} \mathrm{E}_{t} \widehat{s}_{t+1}+\varphi_{b} \widehat{b}_{t} \\
& +\left(\varphi_{s}+\varphi_{x} / 2\right) \mathrm{E}_{t}\left(\widehat{\kappa}_{t+1}+\widehat{\Lambda}_{t, t+1}\right)+\varphi_{\chi}\left(\widehat{\chi}_{t}-(\rho-s) \beta \widehat{\chi}_{t+1}\right)+\widehat{\varepsilon}_{t}^{w}
\end{aligned}
$$

where

$$
\begin{aligned}
& \varphi_{a}=\chi p^{w} \bar{a} \bar{w}^{-1}, \quad \varphi_{x}=\chi \beta \bar{\kappa} x^{2} \bar{w}^{-1}, \quad \varphi_{b}=(1-\chi) \bar{b} \bar{w}^{-1} \\
& \varphi_{s}=(1-\chi) s \beta \bar{H} \bar{w}^{-1}, \quad \varphi_{\chi}=\chi(1-\chi)^{-1} \bar{\kappa} x \bar{w}^{-1} \\
& \widehat{\varepsilon}_{t}^{w}=\varphi_{\eta}\left[1-(\rho-s) \beta \rho^{\eta}\right] \widehat{\varepsilon}_{t}^{\eta}, \quad \varphi_{\eta}=\varphi_{\chi}(1-\chi)(1-\eta)^{-1}
\end{aligned}
$$

- Aggregate wage

$$
\widehat{w}_{t}=\gamma_{b}\left(\widehat{w}_{t-1}-\widehat{\pi}_{t}+\gamma \widehat{\pi}_{t-1}-\widehat{\varepsilon}_{t}^{z}\right)+\gamma_{o} \widehat{w}_{t}^{o}+\gamma_{f} \mathrm{E}_{t}\left(\widehat{w}_{t+1}+\widehat{\pi}_{t+1}-\gamma \widehat{\pi}_{t}+\widehat{\varepsilon}_{t+1}^{z}\right)
$$

where

$$
\begin{aligned}
& \gamma_{b}=\left(1+\tau_{2}\right) \phi^{-1}, \quad \gamma_{o}=\varsigma \phi^{-1}, \quad \gamma_{f}=\left(\tau \lambda^{-1}-\tau_{1}\right) \phi^{-1} \\
& \phi=\left(1+\tau_{2}\right)+\varsigma+\left(\tau \lambda^{-1}-\tau_{1}\right), \quad \varsigma=(1-\lambda)(1-\tau) \lambda^{-1} \\
& \tau_{1}=\left[\varkappa_{w} \mu \varphi_{x}+\varphi_{\chi}(1-\chi)(x \beta \lambda)\left(\varkappa_{w} \mu\right) \mu(\rho \beta)+\varphi_{s} \Gamma\right](1-\tau) \\
& \tau_{2}=-\left(\varkappa_{w} \mu\right) \varphi_{\chi}(1-\chi)(x \beta \lambda) \mu(1-\tau) \\
& \Gamma=(1-\eta x \beta \lambda \mu) \eta^{-1} \mu \varkappa_{w}
\end{aligned}
$$

- Phillips curve

$$
\widehat{\pi}_{t}=\iota_{b} \widehat{\pi}_{t-1}+\iota_{o}\left(\widehat{p}_{t}^{w}+\widehat{\varepsilon}_{t}^{p}\right)+\iota_{f} \mathrm{E}_{t} \widehat{\pi}_{t+1}
$$

where

$$
\begin{aligned}
& \iota_{b}=\gamma^{p}\left(\phi^{p}\right)^{-1}, \quad \iota_{o}=\left(\varsigma^{p} / \tau^{p}\right)\left(\phi^{p}\right)^{-1}, \quad \iota_{f}=\beta\left(\phi^{p}\right)^{-1} \\
& \phi^{p}=1+\beta \gamma^{p}, \quad \varsigma^{p}=\left(1-\lambda^{p}\right)\left(1-\lambda^{p} \beta\right)\left(\lambda^{p}\right)^{-1}, \quad \tau^{p}=1+\left(\varepsilon^{p}-1\right) \xi
\end{aligned}
$$


- Monetary policy rule

$$
\widehat{r}_{t}=\rho_{s} \widehat{r}_{t-1}+\left(1-\rho_{s}\right)\left[r_{\pi} \widehat{\pi}_{t}+r_{y}\left(\widehat{y}_{t}-\widehat{y}_{n t}\right)\right]+\widehat{\varepsilon}_{t}^{r}
$$

- Government spending

$$
\widehat{g}_{t}=\widehat{y}_{t}+\frac{1-y_{g}}{y_{g}} \widehat{\varepsilon}_{t}^{g}
$$

- Market tightness

$$
\widehat{\theta}_{t}=\widehat{v}_{t}-\widehat{u}_{t}
$$

- Benefits

$$
\widehat{b}_{t}=\widehat{k}_{t}^{p}
$$




\section{B Data appendix}

\section{B.1 United States}

GDP Real Gross Domestic Product in billions of chained 2005 dollars. Source: FRED database, Federal Reserve Bank of St. Louis. Divided by population to obtain real per capita GDP.

Investment Fixed Private Investment + Personal Consumption Expenditures: Durable Goods. Source: FRED database, Federal Reserve Bank of St. Louis. Deflated by the GDP price deflator and divided by population to obtain real per capita Investment.

Consumption Personal Consumption Expenditures: Nondurable Goods + Services. Source: FRED database, Federal Reserve Bank of St. Louis. Deflated by the GDP price deflator and divided by population to obtain real per capita Consumption.

Wages Hourly compensation in the Nonfarm Business Sector. Seasonally adjusted. Source: FRED database, Federal Reserve Bank of St. Louis. Divided by the GDP price deflator to obtain an hourly real wage.

Price level Implicit Price Deflator, index numbers, 2005=100. Seasonally adjusted. Source: FRED database, Federal Reserve Bank of St. Louis. Expressed in quarter to quarter growth rates.

Interest Rate Effective Federal Funds Rate. Source: FRED Database, Federal Reserve Bank of St. Louis.

Unemployment Number of unemployed persons. Source: FRED Database, Federal Reserve Bank of St. Louis.

Unemployment Rate Civilian unemployment rate. Source: FRED Database, Federal Reserve Bank of St. Louis.

Vacancies Quarterly average of the monthly composite Help-Wanted index. Source: Barnichon (2010).

Population Civilian Noninstitutional Population. Average of monthly figures. Source: Source: FRED Database, Federal Reserve Bank of St. Louis. 


\section{B.2 United Kingdom}

GDP Real Gross Domestic Product in billions of chained 2005 pounds. Seasonally adjusted. Source: OECD.Stat, Monthly Economic Indicators, April 2012. Divided by population to obtain real per capita GDP.

Investment Real Gross Fixed Capital Formation in billions of chained 2005 pounds. Seasonally adjusted. Source: OECD.Stat, Monthly Economic Indicators, April 2012. Divided by population to obtain real per capita investment.

Consumption Real Private Consumption Expenditure in billions of chained 2005 pounds. Seasonally adjusted. Source: OECD.Stat, Monthly Economic Indicators, April 2012. Divided by population to obtain real per capita consumption.

Wages Wages and Salaries divided by Total actual weekly hours worked. Source: Office for National Statistics (ONS). Deflated by the price level to obtain real hourly compensation.

Price level Implicit Price Deflator, index numbers, 2005=100. Seasonally adjusted. Source: OECD.Stat, Monthly Economic Indicators, April 2012.

Interest Rate Three month interbank offer rate. Quarterly data are averages of monthly figures. Source: OECD.Stat, Monthly Economic Indicators, April 2012

Unemployment Harmonised Unemployment Level. Source: OECD.Stat, Monthly Economic Indicators, April 2012.

Unemployment Rate Harmonized Unemployment Rate. Source: OECD.Stat, Monthly Economic Indicators, April 2012

Vacancies Data refer to job opportunities notified by an employer to a Jobcentre or Careers Office (including self-employed opportunities created by employers) which remained unfilled on the day of the count. The vacancy figures do not represent the total number of vacancies in the economy. Recent estimates suggest that nationally about one third of all vacancies are notified to jobcentres. The suspension of the series in April 1999 was initially due to the discontinuity of vacancy figures for Northern Ireland identified during the introduction of major new computer system. Figures should be available anew from October 2001 but are still provisional and subject to future adjustment. Source: OECD.Stat, Monthly Economic Indicators, April 2012. Due to the presence of a break in the mean of the series in 2001Q1, we have mean corrected the series by assuming that there were no changes in vacancies between 2001Q1 and 2001Q2.

Population Thousands of population between age 15 to 64 . Data refer to annual average estimates. Source: OECD.Stat Annual Labour Force Statistics. Annual values are taken as second quarter values and quarterly data are interpolated linearly until 2010. After the second quarter of 2010, data are extrapolated. 


\section{B.3 Sweden}

GDP Real Gross Domestic Product, constant prices. Seasonally adjusted. Source: Statistics Sweden. Divided by population to obtain real per capita GDP.

Investment Real Gross Fixed Capital Formation, constant prices. Seasonally adjusted. Source: Statistics Sweden. Divided by population to obtain real per capita investment.

Consumption Final Private Consumption Expenditure, constant prices. Seasonally adjusted. Source: Statistics Sweden. Divided by population to obtain real per capita consumption.

Wages Hourly compensation. Seasonally adjusted, not working day adjusted. Source: Statistics Sweden.

Price level Consumer Price Index with Fixed Interest Rate (CPIF). Quarterly averages. Seasonally adjusted. Source: Statistics Sweden.

Interest Rate Repo rate. Quarterly averages. Source: Sveriges Riksbank.

Unemployment Number of unemployed. Quarterly averages. Seasonally adjusted. Source: Statistics Sweden.

Unemployment Rate Quarterly averages. Seasonally adjusted. Source: Statistics Sweden.

Vacancies Quarterly averages. Seasonally adjusted. Source: OECD.Stat, Monthly Economic Indicators, April 2012

Population Population between age 16 to 64. Source: Statistics Sweden. 


\section{B.4 Germany}

GDP Real Gross Domestic Product in billions of chained 2005 euros. Seasonally adjusted. Source: OECD.Stat, Monthly Economic Indicators, April 2012. Divided by population to obtain real per capita GDP.

Investment Real Gross Fixed Capital Formation in billions of chained 2005 euros. Seasonally adjusted. Source: OECD.Stat, Monthly Economic Indicators, April 2012. Divided by population to obtain real per capita investment.

Consumption Real Private Consumption Expenditure in billions of chained 2005 euros. Seasonally adjusted. Source: OECD.Stat, Monthly Economic Indicators, April 2012. Divided by population to obtain real per capita consumption.

Wages Hourly compensation. Seasonally adjusted, not working day adjusted. Source: European Central Bank.

Price level Implicit Price Deflator, index numbers, $2005=100$. Seasonally adjusted. Source: OECD.Stat, Monthly Economic Indicators, April 2012.

Interest Rate Three month interbank offer rate. Data refer to unified Germany from July 1990 and western Germany prior to this date. Source: OECD.Stat, Monthly Economic Indicators, April 2012

Unemployment Number of unemployed. Source: OECD.Stat, Monthly Economic Indicators, April 2012.

Unemployment Rate From 2005, data are supplied by Eurostat and seasonally adjusted by OECD. Prior to 2005, the source for original data is the Federal Statistical Office of Germany and the Federal Bank of Germany for seasonally adjusted series. Source: OECD.Stat, Monthly Economic Indicators, April 2012

Vacancies Data refer to vacancies for jobs of 7 days' duration or more reported by employers to employment agencies to be filled within 3 months and remaining unfilled at the end of the month. Source: OECD.Stat, Monthly Economic Indicators, April 2012

Population Thousands of population between age 15 to 64 . Data refer to annual average estimates. Source: OECD.Stat Annual Labour Force Statistics. Annual values are taken as second quarter values and quarterly data are interpolated linearly until 2010. After the second quarter of 2010, data are extrapolated. 


\section{References}

An, Sungbae and Frank Schorfheide (2007), "Bayesian analysis of DSGE models," Econometric Reviews 26 (2-4), 113-172.

Barnichon, Regis (2010), "Building a composite help-wanted index," Economics Letters 109, $175-178$.

Barnichon, Regis and Andrew Figura (2012), "The determinants of the cycles and trends in U.S. unemployment," Unpublished manuscript, CREI.

Barnichon, Regis and Andrew Figura (2011), "Labor market heterogeneities, matching efficiency and the cyclical behavior of the job finding rate," Unpublished manuscript, CREI.

Bernanke, Ben, Mark Gertler, and Simon Gilchrist (1999), "The Financial Accelerator in a Quantitative Business Cycle Framework," in Handbook of Macroeconomics, edited by John B. Taylor and Michael Woodford, Elsevier Science.

Burda, Michael C. and Jennifer Hunt (2011), "What explains the German labor market miracle in the Great Recession?" Brookings Papers on Economic Activity, Spring 2011, 273-319.

Calvo, Guillermo A. (1983), "Staggered prices in a utility-maximizing framework," Journal of Monetary Economics 12 (3), 383-398.

Canova, Fabio and Luca Sala (2009), "Back to square one: identification issues in DSGE models," Journal of Monetary Economics 56 (4), 431-449.

Christiano, Lawrence J., Martin Eichenbaum, and Charles L. Evans (2005), "Nominal rigidities and the dynamic effects of a shock to monetary policy," Journal of Political Economy 113 (1), 1-45.

Christiano, Lawrence J., Roberto Motto, and Massimo Rostagno (2003), "The great depression and the Friedman-Schwartz hypothesis," Journal of Money, Credit, and Banking 35 (6, Part 2), 1119-1198.

Christiano, Lawrence J., Roberto Motto, and Massimo Rostagno (2008), "Shocks, structures or monetary policies? The euro area and US after 2001," Journal of Economic Dynamics and Control 32 (8), 2476-2506.

Christiano, Lawrence J., Matthias Trabandt and Karl Walentin (2011), "Introducing financial frictions and unemployment into a small open economy model," Journal of Economic Dynamics and Control 35 (12), 1999-2041.

Davis, Steven J., R. Jason Faberman, and John C. Haltiwanger (2012), "Recruiting intensity during and after the Great Recession: National and industry evidence," Working Paper No. 17782, National Bureau of Economic Research.

Daly, Mary C., Bart Hobijn, Ayşegül Şahin, and Robert G. Valletta (2012), "A search and matching approach to labor markets: Did the natural rate of unemployment rise?," Journal of Economic Perspectives 26 (3), 3-26.

Elsby, Michael, Bart Hobijn, and Ayşegül Şahin (2012), "Unemployment dynamics in the OECD," Forthcoming, Review of Economics and Statistics. 
Fahr, René and Uwe Sunde (2009), "Did the Hartz reforms speed-up the matching process? A macro-evaluation using empirical matching functions," German Economic Review $10(3), 284-316$.

Furlanetto, Francesco and Nicolas Groshenny (2012a), "Matching efficiency and business cycle fluctuations," Working Paper No. 34/2012, Centre for Applied Macroeconomic Analysis, The Australian National University.

Furlanetto, Francesco and Nicolas Groshenny (2012b), "Mismatch shocks and unemployment during the Great Recession," Unpublished manuscript, Norges Bank.

Galí, Jordi, Frank Smets, and Raf Wouters (2011), "Unemployment in an estimated New Keynesian model," Forthcoming, NBER Macroeconomics Annual 2011.

Galí, Jordi, Frank Smets, and Raf Wouters (2012), "Slow recoveries: A structural interpretation," Unpublished manuscript, Universitat Pompeu Fabra.

Gertler, Mark, Luca Sala, and Antonella Trigari (2008), "An estimated monetary DSGE model with unemployment and staggered nominal wage bargaining," Journal of Money, Credit, and Banking 40 (8), 1713-1764.

Gertler, Mark and Antonella Trigari (2009), "Unemployment fluctuations with staggered Nash wage bargaining," Journal of Political Economy 117 (1), 38-86.

Guerrieri, Veronica and Guido Lorenzoni (2011) "Credit crises, precautionary savings, and the liquidity trap," Unpublished manuscript, University of Chicago and MIT.

Hall, Robert E. (2012), "Quantifying the forces leading to the collapse of GDP after the financial crisis," Unpublished manuscript, Stanford University.

International Monetary Fund (2010), "Unemployment dynamics during recessions and recoveries: Okun's law and beyond," World Economic Outlook: Rebalancing Growth, Ch. 3.

Justiniano, Alejandro and Claudio Michelacci (2012), "The cyclical behavior of equilibrium unemployment and vacancies in the United States and Europe," in Frankel, Jeffrey, and Christopher Pissarides (eds.), NBER International Seminar on Macroeconomics 2011.

Justiniano, Alejandro, Giorgio E. Primiceri, and Andrea Tambalotti (2010), "Investment shocks and business cycles," Journal of Monetary Economics 57 (2), 132-145.

Justiniano, Alejandro, Giorgio E. Primiceri, and Andrea Tambalotti (2012), "Is there a trade-off between inflation and output stabilization?," Unpublished manuscript, Northwestern University.

Kimball, Miles S. (1995), "The quantitative analytics of the basic neomonetarist model," Journal of Money, Credit, and Banking 27 (4), 1241-1277.

Kocherlakota, Narayana (2010), "Inside the FOMC," Speech in Marquette, Michigan, August 17, 2010, Federal Reserve Bank of Minneapolis.

Krause, Michael U. and Harald Uhlig (2012), "Transitions in the German labor market: Structure and crisis," Journal of Monetary Economics 59 (1), 64-79.

Kuang, Katherine and Rob Valletta (2010), "Extended unemployment and UI benefits," Economic Letter 2010-12, Federal Reserve Bank of San Francisco. 
Merz, Monika (1995), "Search in the labor market and the real business cycle," Journal of Monetary Economics 36 (2), 269-300.

Monacelli, Tommaso, Vincenzo Quadrini, and Antonella Trigari (2011), "Financial markets and unemployment," Unpublished manuscript, Università Bocconi.

Mortensen, Dale T. and Christopher A. Pissarides (1994), "Job creation and job destruction in the theory of unemployment," Review of Economic Studies, 61 (3), 397-415.

Petrongolo, Barbara and Christopher A. Pissarides (2001), "Looking into the black box: A survey of the matching function," Journal of Economic Literature 39 (2), 390-431.

Şahin, Ayşegül, Joseph Song, Giorgio Topa, and Giovanni L. Violante (2011) "Measuring mismatch in the U.S. labor market," Unpublished manuscript, Federal Reserve Bank of New York.

Sala, Luca, Ulf Söderström, and Antonella Trigari (2008), "Monetary policy under uncertainty in an estimated model with labor market frictions," Journal of Monetary Economics, 55 (5), 983-1006.

Sala, Luca, Ulf Söderström, and Antonella Trigari (2010), "The output gap, the labor wedge, and the dynamic behaviour of hours," Discussion Paper No. 8005, Centre for Economic Policy Research.

Silva, José I. and Manuel Toledo (2009), "Labor turnover costs and the cyclical behavior of vacancies and unemployment," Macroeconomic Dynamics 13 (S1), 76-96.

Smets, Frank and Raf Wouters (2003), "An estimated dynamic stochastic general equilibrium model of the Euro area," Journal of the European Economic Association 1 (5), $1123-1175$.

Smets, Frank and Raf Wouters (2007), "Shocks and frictions in U.S. business cycles: A Bayesian DSGE approach," American Economic Review 97 (3), 586-606.

Sterk, Vincent (2011), "Home Equity, Mobility and Macroeconomic Fluctuations," Unpublished manuscript, UCL.

Yashiv, Eran (2000), "The determinants of equilibrium unemployment," American Economic Review 90 (5), 1297-1322. 
Table 1: Calibrated parameters

\begin{tabular}{lcllll}
\hline \hline & & U.S. & U.K. & Sweden & Germany \\
\hline Discount factor & $\beta$ & 0.99 & 0.99 & 0.99 & 0.99 \\
Capital depreciation rate & $\delta$ & 0.025 & 0.025 & 0.025 & 0.025 \\
Capital share & $\alpha$ & 0.33 & 0.33 & 0.33 & 0.33 \\
Government spending to output ratio & $G / Y$ & 0.20 & 0.20 & 0.30 & 0.19 \\
Steady-state growth rate & $\gamma_{z}$ & 1.0048 & 1.0064 & 1.0068 & 1.0036 \\
Job survival probability & $\rho$ & 0.897 & 0.97 & 0.95 & 0.984 \\
Job finding probability & $s$ & 0.625 & 0.283 & 0.392 & 0.146 \\
Matching function elasticity & $\sigma$ & 0.5 & 0.5 & 0.5 & 0.5 \\
Price indexing & $\gamma_{p}$ & 0 & 0 & 0 & 0 \\
\hline
\end{tabular}

This table reports the calibrated parameters in the estimated models. 
Table 2: Prior distribution and estimated posterior distribution, structural parameters

\begin{tabular}{|c|c|c|c|c|c|c|}
\hline & & & U.S. & U.K. & Sweden & Germany \\
\hline Utilization rate elasticity & $\psi_{\nu}$ & $\mathrm{B}(0.5,0.1)$ & $\begin{array}{c}0.85 \\
{[0.76,0.91]}\end{array}$ & $\begin{array}{c}0.78 \\
{[0.68,0.87]}\end{array}$ & $\begin{array}{c}0.78 \\
{[0.67,0.87]}\end{array}$ & $\begin{array}{c}0.45 \\
{[0.33,0.57]}\end{array}$ \\
\hline Capital adjustment cost elasticity & $\eta_{k}$ & $\mathrm{~N}(4,1.5)$ & $\begin{array}{c}4.02 \\
{[2.33,5.80]}\end{array}$ & $\begin{array}{c}3.35 \\
{[0.96,5.61]}\end{array}$ & $\begin{array}{c}4.43 \\
{[2.65,6.39]}\end{array}$ & $\begin{array}{c}2.19 \\
{[0.99,4.01]}\end{array}$ \\
\hline Habit parameter & $h$ & $\mathrm{~B}(0.5,0.1)$ & $\begin{array}{c}0.58 \\
{[0.51,0.65]}\end{array}$ & $\begin{array}{c}0.32 \\
{[0.22,0.42]}\end{array}$ & $\begin{array}{c}0.45 \\
{[0.33,0.57]}\end{array}$ & $\begin{array}{c}0.14 \\
{[0.08,0.22]}\end{array}$ \\
\hline Steady-state bargaining power & $\eta$ & $\mathrm{B}(0.5,0.1)$ & $\begin{array}{c}0.90 \\
{[0.85,0.94]}\end{array}$ & $\begin{array}{c}0.78 \\
{[0.65,0.89]}\end{array}$ & $\begin{array}{c}0.79 \\
{[0.67,0.89]}\end{array}$ & $\begin{array}{c}0.76 \\
{[0.67,0.83]}\end{array}$ \\
\hline Rel. flow value of unemployment & $\widetilde{b}$ & $\mathrm{~B}(0.5,0.1)$ & $\begin{array}{c}0.73 \\
{[0.63,0.81]}\end{array}$ & $\begin{array}{c}0.90 \\
{[0.81,0.94]}\end{array}$ & $\begin{array}{c}0.86 \\
{[0.76,0.92]}\end{array}$ & $\begin{array}{c}0.54 \\
{[0.38,0.67]}\end{array}$ \\
\hline Weight on hiring costs & $\eta_{q}$ & $\mathrm{G}(0.145,0.1)$ & $\begin{array}{c}0.49 \\
{[0.20,0.86]}\end{array}$ & $\begin{array}{c}0.16 \\
{[0.03,0.36]}\end{array}$ & $\begin{array}{c}0.10 \\
{[0.02,0.26]}\end{array}$ & $\begin{array}{c}1.18 \\
{[1.10,1.27]}\end{array}$ \\
\hline Calvo wage parameter & $\lambda_{w}$ & $\mathrm{~B}(0.75,0.1)$ & $\begin{array}{c}0.68 \\
{[0.58,0.78]}\end{array}$ & $\begin{array}{c}0.66 \\
{[0.55,0.78]}\end{array}$ & $\begin{array}{c}0.70 \\
{[0.60,0.80]}\end{array}$ & $\begin{array}{c}0.74 \\
{[0.67,0.79]}\end{array}$ \\
\hline Calvo price parameter & $\lambda_{p}$ & $\mathrm{~B}(0.66,0.1)$ & $\begin{array}{c}0.82 \\
{[0.75,0.88]}\end{array}$ & $\begin{array}{c}0.63 \\
{[0.51,0.75]}\end{array}$ & $\begin{array}{c}0.75 \\
{[0.60,0.87]}\end{array}$ & $\begin{array}{c}0.74 \\
{[0.66,0.80]}\end{array}$ \\
\hline Wage indexing parameter & $\gamma_{w}$ & $\mathrm{U}(0,1)$ & $\begin{array}{c}0.15 \\
{[0.01,0.49]}\end{array}$ & $\begin{array}{c}0.13 \\
{[0.01,0.36]}\end{array}$ & $\begin{array}{c}0.11 \\
{[0.01,0.32]}\end{array}$ & $\begin{array}{c}0.13 \\
{[0.01,0.44]}\end{array}$ \\
\hline Steady-state price markup & $\varepsilon^{p}$ & $\mathrm{~N}(1.15,0.05)$ & $\begin{array}{c}1.30 \\
{[1.24,1.36]}\end{array}$ & $\begin{array}{c}1.26 \\
{[1.18,1.33]}\end{array}$ & $\begin{array}{c}1.26 \\
{[1.18,1.34]}\end{array}$ & $\begin{array}{c}1.49 \\
{[1.43,1.55]}\end{array}$ \\
\hline Mon. pol. response to inflation & $r_{\pi}$ & $\mathrm{N}(1.7,0.3)$ & $\begin{array}{c}1.76 \\
{[1.25,2.25]}\end{array}$ & $\begin{array}{c}1.57 \\
{[1.06,2.06]}\end{array}$ & $\begin{array}{c}1.54 \\
{[1.00,2.05]}\end{array}$ & $\begin{array}{c}1.88 \\
{[1.55,2.30]}\end{array}$ \\
\hline Mon. pol. response to output gap & $r_{y}$ & $\mathrm{G}(0.125,0.1)$ & $\begin{array}{c}0.31 \\
{[0.22,0.44]}\end{array}$ & $\begin{array}{c}0.51 \\
{[0.29,0.82]}\end{array}$ & $\begin{array}{c}0.39 \\
{[0.22,0.65]}\end{array}$ & $\begin{array}{c}0.27 \\
{[0.16,0.48]}\end{array}$ \\
\hline Mon. pol. inertia & $\rho_{s}$ & $\mathrm{~B}(0.75,0.1)$ & $\begin{array}{c}0.73 \\
{[0.61,0.80]}\end{array}$ & $\begin{array}{c}0.73 \\
{[0.61,0.82]}\end{array}$ & $\begin{array}{c}0.85 \\
{[0.75,0.91]}\end{array}$ & $\begin{array}{c}0.70 \\
{[0.60,0.79]}\end{array}$ \\
\hline
\end{tabular}

This table reports the prior distribution and the median and the 5th and 95th percentiles (within square brackets) of the estimated posterior distribution of the structural parameters. For the prior, the two numbers in parentheses are the mean and the standard deviation of the distribution, except for the uniform distribution, where the numbers are the lower and upper bounds of the distribution. 
Table 3: Prior distribution and estimated posterior distribution, shock parameters

\begin{tabular}{|c|c|c|c|c|c|c|}
\hline & & & U.S. & U.K. & Sweden & Germany \\
\hline \multicolumn{7}{|c|}{ (a) Autoregressive parameters } \\
\hline \multirow[t]{2}{*}{ Risk premium } & $\rho_{b}$ & $\mathrm{~B}(0.5 .0 .15)$ & 0.88 & 0.76 & 0.82 & 0.94 \\
\hline & & & {$[0.82,0.93]$} & {$[0.63,0.87]$} & {$[0.68,0.91]$} & {$[0.88,0.97]$} \\
\hline \multirow[t]{2}{*}{ Monetary policy } & $\rho_{r}$ & $\mathrm{~B}(0.5 .0 .15)$ & 0.45 & 0.67 & 0.68 & 0.62 \\
\hline & & & {$[0.30,0.68]$} & {$[0.49,0.83]$} & {$[0.51,0.81]$} & {$[0.28,0.86]$} \\
\hline \multirow[t]{2}{*}{ Investment } & $\rho_{i}$ & $\mathrm{~B}(0.5 .0 .15)$ & 0.82 & 0.68 & 0.62 & 0.15 \\
\hline & & & {$[0.74,0.89]$} & {$[0.52,0.85]$} & {$[0.39,0.82]$} & {$[0.08,0.25]$} \\
\hline \multirow[t]{2}{*}{ Govt \& net exports } & $\rho_{g}$ & $\mathrm{~B}(0.5 .0 .15)$ & 0.99 & 0.99 & 0.87 & 0.97 \\
\hline & & & {$[0.98,0.99]$} & {$[0.97,0.99]$} & {$[0.76,0.95]$} & {$[0.92,0.98]$} \\
\hline \multirow[t]{2}{*}{ Technology } & $\rho_{z}$ & $\mathrm{~B}(0.5 .0 .15)$ & 0.15 & 0.21 & 0.18 & 0.19 \\
\hline & & & {$[0.08,0.24]$} & {$[0.11,0.33]$} & {$[0.09,0.31]$} & {$[0.10,0.29]$} \\
\hline \multirow[t]{2}{*}{ Price markup } & $\rho_{p}$ & $\mathrm{~B}(0.5 .0 .15)$ & 0.21 & 0.13 & 0.14 & 0.06 \\
\hline & & & {$[0.10,0.36]$} & {$[0.06,0.23]$} & {$[0.06,0.29]$} & {$[0.03,0.13]$} \\
\hline \multirow[t]{2}{*}{ Bargaining power } & $\rho_{\eta}$ & $\mathrm{B}(0.5 .0 .15)$ & 0.50 & 0.50 & 0.48 & 0.93 \\
\hline & & & {$[0.26,0.78]$} & {$[0.25,0.73]$} & {$[0.24,0.74]$} & {$[0.87,0.96]$} \\
\hline \multirow[t]{2}{*}{ Matching efficiency } & $\rho_{m}$ & $\mathrm{~B}(0.5 .0 .15)$ & 0.73 & 0.54 & 0.46 & 0.42 \\
\hline & & & {$[0.61,0.83]$} & {$[0.38,0.69]$} & {$[0.30,0.63]$} & {$[0.29,0.56]$} \\
\hline \multicolumn{7}{|c|}{ (b) Standard deviations of innovations } \\
\hline \multirow[t]{2}{*}{ Risk premium } & $\sigma_{b}$ & $\mathrm{IG}(0.15 .0 .15)$ & 0.28 & 0.23 & 0.46 & 0.14 \\
\hline & & & {$[0.21,0.42]$} & {$[0.14,0.35]$} & {$[0.28,0.97]$} & {$[0.10,0.19]$} \\
\hline \multirow[t]{2}{*}{ Monetary policy } & $\sigma_{r}$ & $\mathrm{IG}(0.15 .0 .15)$ & 0.13 & 0.09 & 0.09 & 0.07 \\
\hline & & & {$[0.11,0.15]$} & {$[0.07,0.12]$} & {$[0.07,0.11]$} & {$[0.05,0.10]$} \\
\hline \multirow[t]{2}{*}{ Investment } & $\sigma_{i}$ & $\mathrm{IG}(0.15 .0 .15)$ & 0.13 & 0.14 & 0.19 & 0.15 \\
\hline & & & {$[0.09,0.19]$} & {$[0.05,0.22]$} & {$[0.11,0.31]$} & {$[0.08,0.26]$} \\
\hline \multirow[t]{2}{*}{ Govt \& net exports } & $\sigma_{g}$ & $\mathrm{IG}(0.15 .0 .15)$ & 0.34 & 0.60 & 0.56 & 0.60 \\
\hline & & & {$[0.30,0.38]$} & {$[0.51,0.71]$} & {$[0.47,0.66]$} & {$[0.45,0.75]$} \\
\hline \multirow[t]{2}{*}{ Technology } & $\sigma_{z}$ & $\mathrm{IG}(0.15 .0 .15)$ & 0.89 & 0.56 & 1.00 & 0.99 \\
\hline & & & {$[0.79,1.00]$} & {$[0.47,0.67]$} & {$[0.85,1.19]$} & {$[0.72,1.36]$} \\
\hline \multirow[t]{2}{*}{ Price markup } & $\sigma_{p}$ & $\mathrm{IG}(0.15 .0 .15)$ & 0.14 & 0.53 & 0.48 & 0.33 \\
\hline & & & {$[0.12,0.17]$} & {$[0.44,0.64]$} & {$[0.40,0.59]$} & {$[0.28,0.40]$} \\
\hline \multirow[t]{2}{*}{ Bargaining power } & $\sigma_{\eta}$ & $\mathrm{IG}(0.15 .0 .15)$ & 0.22 & 0.09 & 0.09 & 0.09 \\
\hline & & & {$[0.12,0.35]$} & {$[0.05,0.15]$} & {$[0.05,0.18]$} & {$[0.06,0.15]$} \\
\hline \multirow[t]{2}{*}{ Matching efficiency } & $\sigma_{m}$ & $\mathrm{IG}(0.15 .0 .15)$ & 4.60 & 6.63 & 7.74 & 17.76 \\
\hline & & & {$[4.12,5.19]$} & {$[5.79,7.62]$} & {$[6.64,9.01]$} & {$[16.80,19.16]$} \\
\hline \multicolumn{7}{|c|}{ (c) Standard deviation of measurement error on real wage growth } \\
\hline \multirow[t]{2}{*}{ U.S. } & & $\mathrm{B}(0.205,0.0649)$ & 0.47 & & & \\
\hline & & & {$[0.34,0.55]$} & & & \\
\hline \multirow[t]{2}{*}{ U.K. } & & $\mathrm{B}(0.296,0.0937)$ & & 0.65 & & \\
\hline & & & & {$[0.57,0.73]$} & & \\
\hline \multirow[t]{2}{*}{ Sweden } & & $\mathrm{B}(0.257,0.0813)$ & & & 0.54 & \\
\hline & & & & & {$[0.46,0.62]$} & \\
\hline \multirow[t]{2}{*}{ Germany } & & $\mathrm{B}(0.237,0.0735)$ & & & & 0.63 \\
\hline & & & & & & {$[0.56,0.71]$} \\
\hline
\end{tabular}

This table reports the prior distribution and the median and the 5th and 95th percentiles (within square brackets) of the estimated posterior distribution of the shock parameters and the measurement error. For the prior, the two numbers in parentheses are the mean and the standard deviation of the distribution. 
Table 4: Variance decompositions

\begin{tabular}{|c|c|c|c|}
\hline Shock & Output growth & Unemployment & Vacancies \\
\hline \multicolumn{4}{|l|}{ (a) U.S. } \\
\hline Risk premium & 0.24 & 0.30 & 0.27 \\
\hline Monetary policy & 0.06 & 0.05 & 0.05 \\
\hline Investment & 0.19 & 0.41 & 0.32 \\
\hline Govt \& net exports & 0.11 & 0.02 & 0.04 \\
\hline Technology & 0.39 & 0.19 & 0.18 \\
\hline Price markup & 0.00 & 0.00 & 0.00 \\
\hline Bargaining power & 0.00 & 0.02 & 0.01 \\
\hline Matching efficiency & 0.01 & 0.02 & 0.13 \\
\hline \multicolumn{4}{|l|}{ (b) U.K. } \\
\hline Risk premium & 0.21 & 0.08 & 0.22 \\
\hline Monetary policy & 0.12 & 0.10 & 0.16 \\
\hline Investment & 0.08 & 0.45 & 0.21 \\
\hline Govt \& net exports & 0.37 & 0.09 & 0.24 \\
\hline Technology & 0.22 & 0.27 & 0.09 \\
\hline Price markup & 0.00 & 0.00 & 0.00 \\
\hline Bargaining power & 0.00 & 0.01 & 0.01 \\
\hline Matching efficiency & 0.00 & 0.01 & 0.07 \\
\hline \multicolumn{4}{|l|}{ (c) Sweden } \\
\hline Risk premium & 0.32 & 0.27 & 0.33 \\
\hline Monetary policy & 0.08 & 0.14 & 0.11 \\
\hline Investment & 0.13 & 0.23 & 0.18 \\
\hline Govt \& net exports & 0.27 & 0.05 & 0.17 \\
\hline Technology & 0.19 & 0.31 & 0.15 \\
\hline Price markup & 0.00 & 0.00 & 0.00 \\
\hline Bargaining power & 0.00 & 0.00 & 0.00 \\
\hline Matching efficiency & 0.00 & 0.00 & 0.06 \\
\hline \multicolumn{4}{|l|}{ (d) Germany } \\
\hline Risk premium & 0.22 & 0.03 & 0.17 \\
\hline Monetary policy & 0.09 & 0.01 & 0.08 \\
\hline Investment & 0.35 & 0.01 & 0.11 \\
\hline Govt \& net exports & 0.18 & 0.00 & 0.04 \\
\hline Technology & 0.11 & 0.03 & 0.05 \\
\hline Price markup & 0.00 & 0.00 & 0.00 \\
\hline Bargaining power & 0.00 & 0.40 & 0.53 \\
\hline Matching efficiency & 0.04 & 0.52 & 0.02 \\
\hline
\end{tabular}

This table shows the contribution of different shocks to the long-run variance of GDP growth, unemployment, and vacancies in the estimated models. 
Figure 1: Output, unemployment, labor productivity, and labor share in four countries, 2005-2011
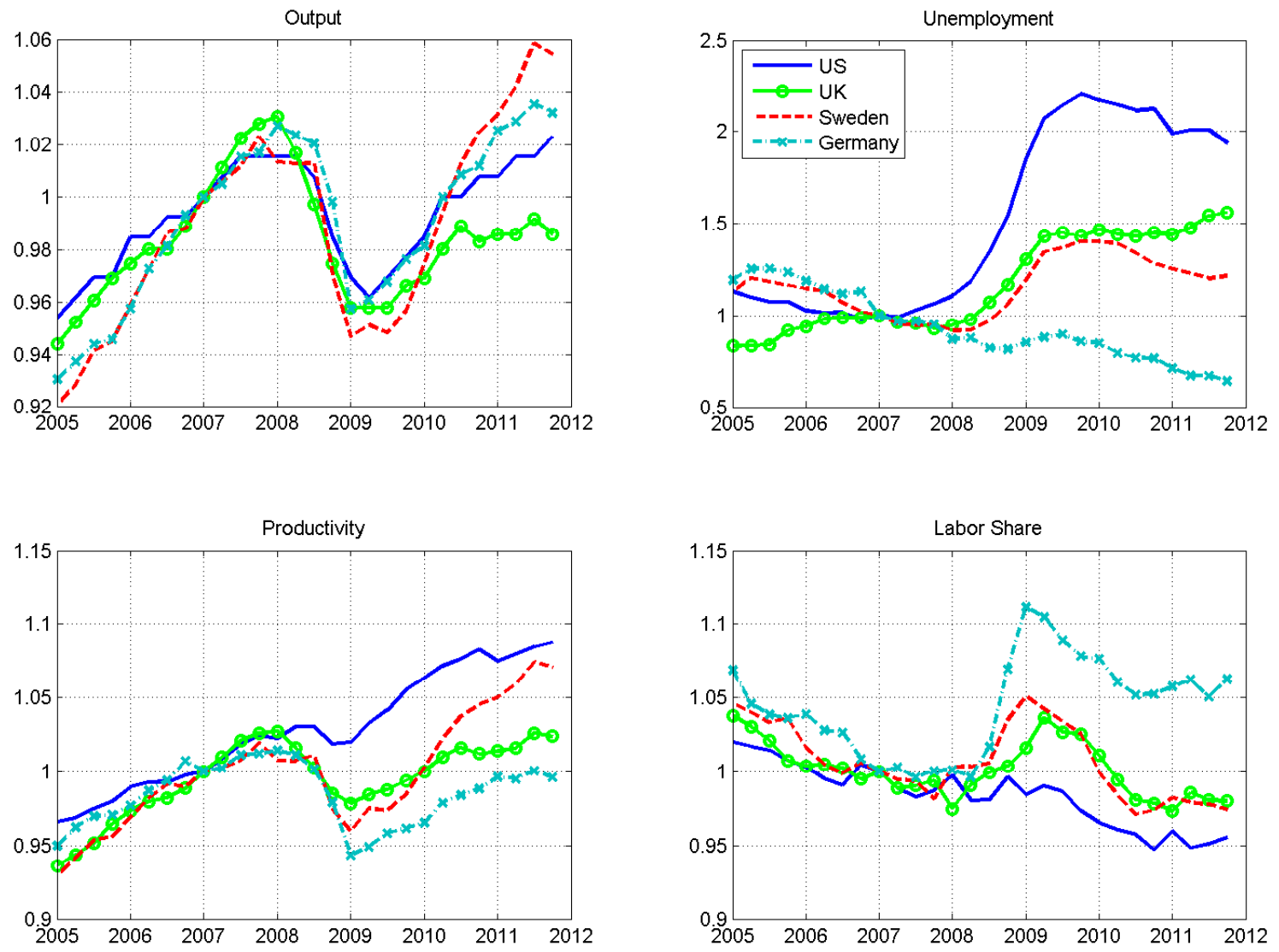

This figure shows the level of GDP, the rate of unemployment, labor productivity (output per worker), and the labor share from 2005Q1 to 2011Q4. All variables are indexed to 1 in 2007Q1. 
Figure 2: Okun's law relationships in four countries, 1995-2011
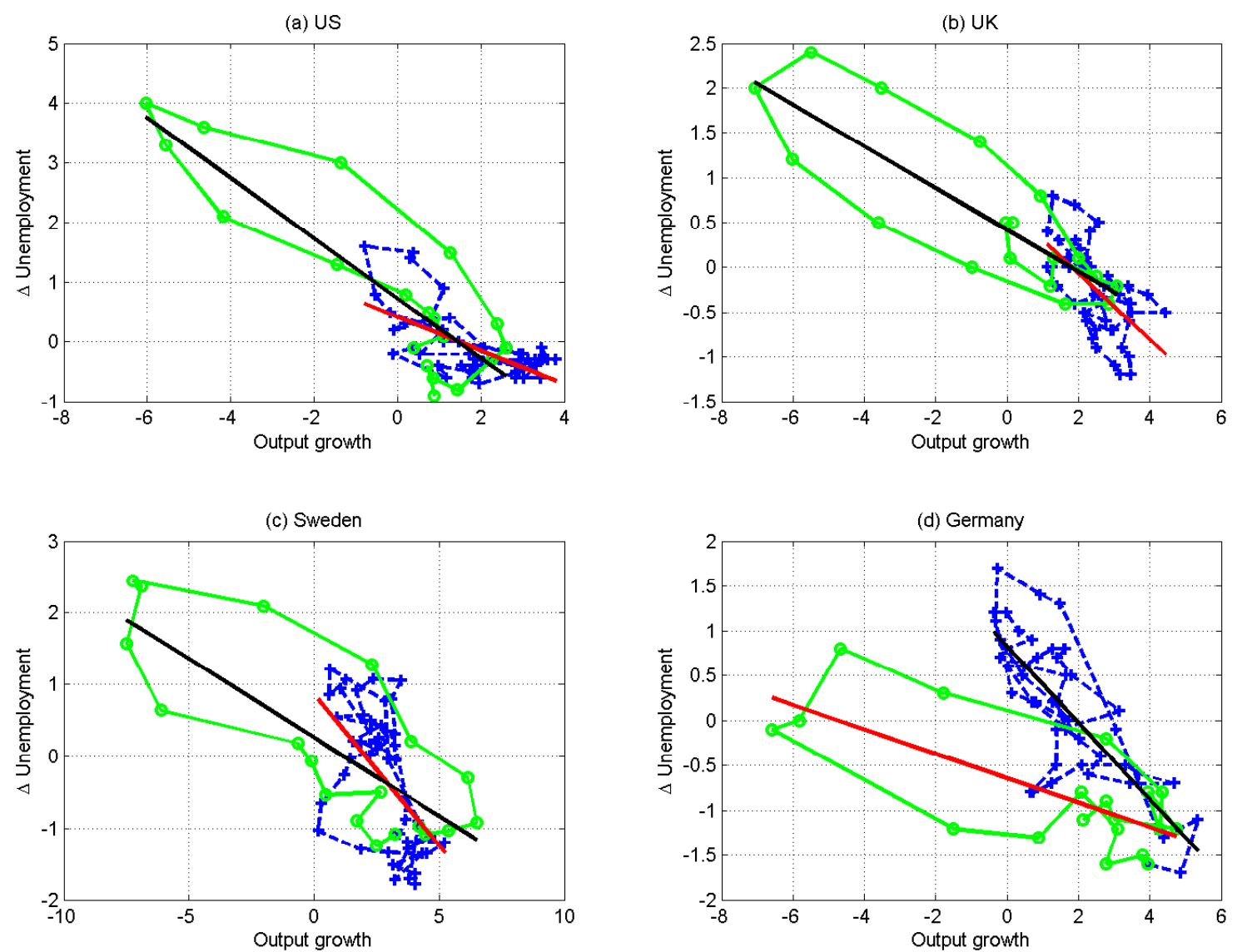

This figure plots the four-quarter growth rate of GDP against the yearly change in the unemployment rate in the period from 1995Q1 until 2011Q4. The blue (dark) sections refer to the period 1995-2006, the green (light) sections to 2007-2011. The black and red lines are regression lines for the two subsamples. 
Figure 3: Beveridge curves in four countries, 1995-2011
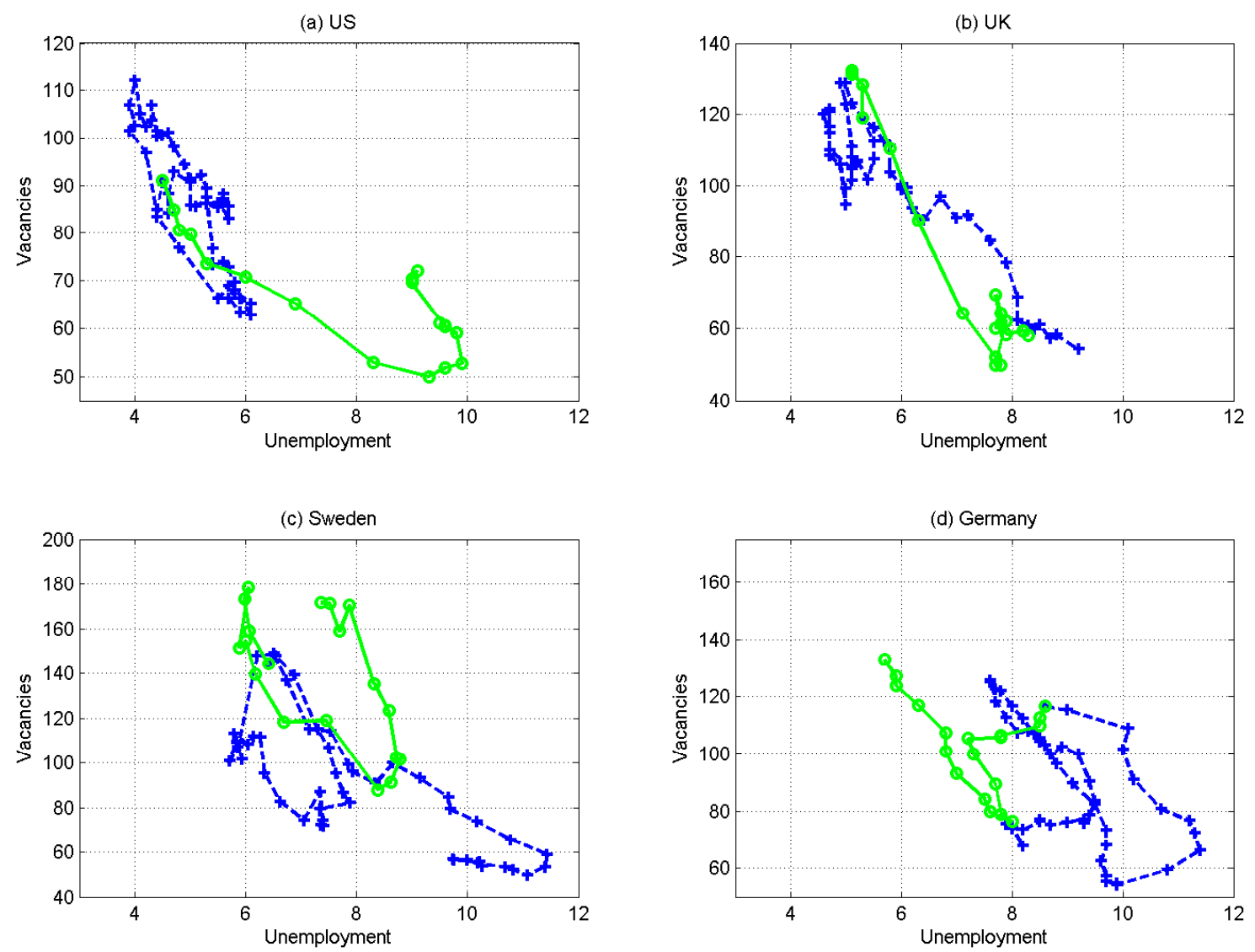

This figure plots the rate of unemployment against the level of vacancies in the period from 1995Q1 until 2011Q4. Vacancies are indexed to 100 in 2008Q4. The blue (dark) sections refer to the period 1995-2006, the green (light) sections to 2007-2011. 
Figure 4: Estimated shocks, U.S.
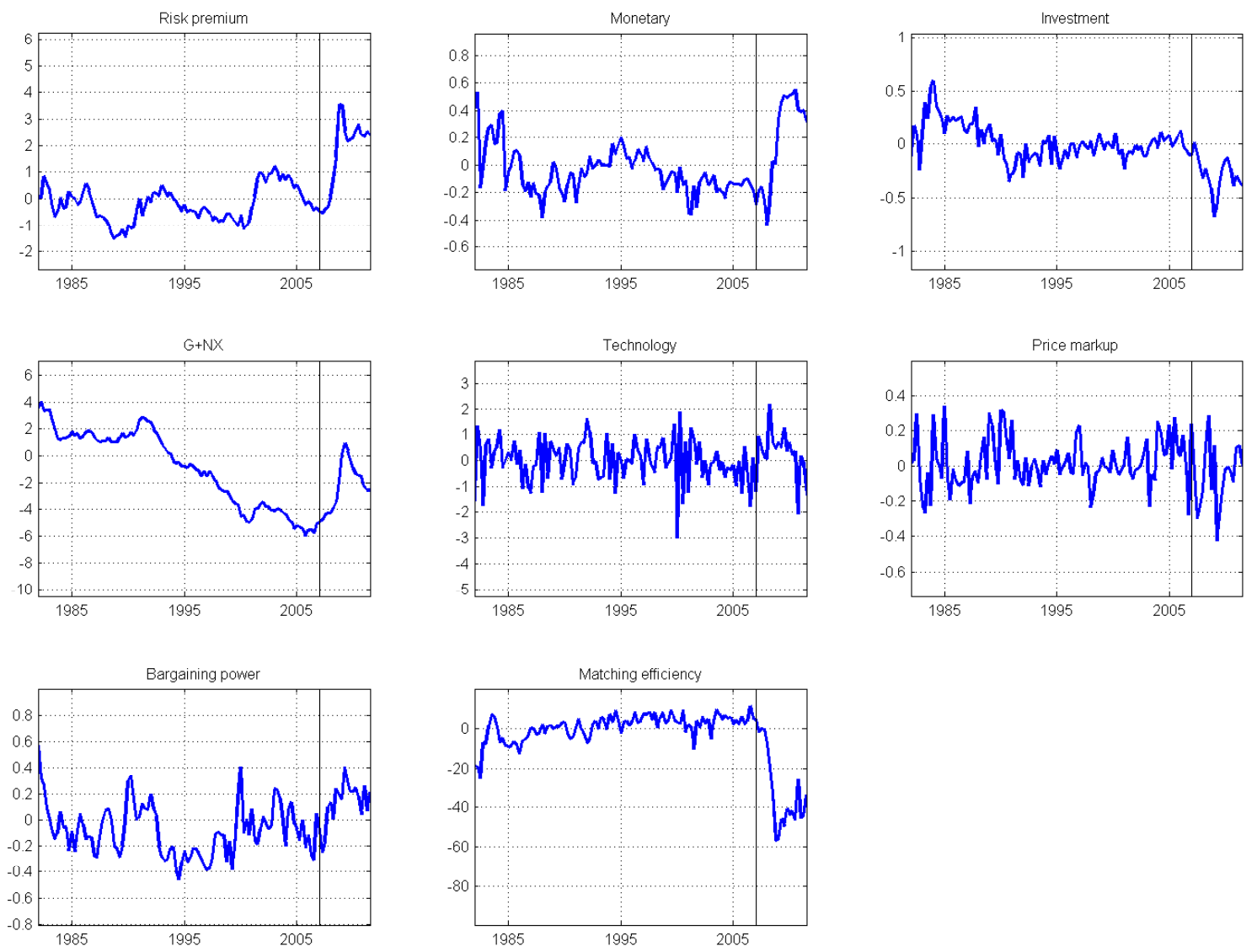

This figure shows the estimated time-series processes for the structural shocks in the U.S. The vertical line corresponds to 2007Q1, the last period in the sample used for estimation. 
Figure 5: Estimated shocks, U.K.
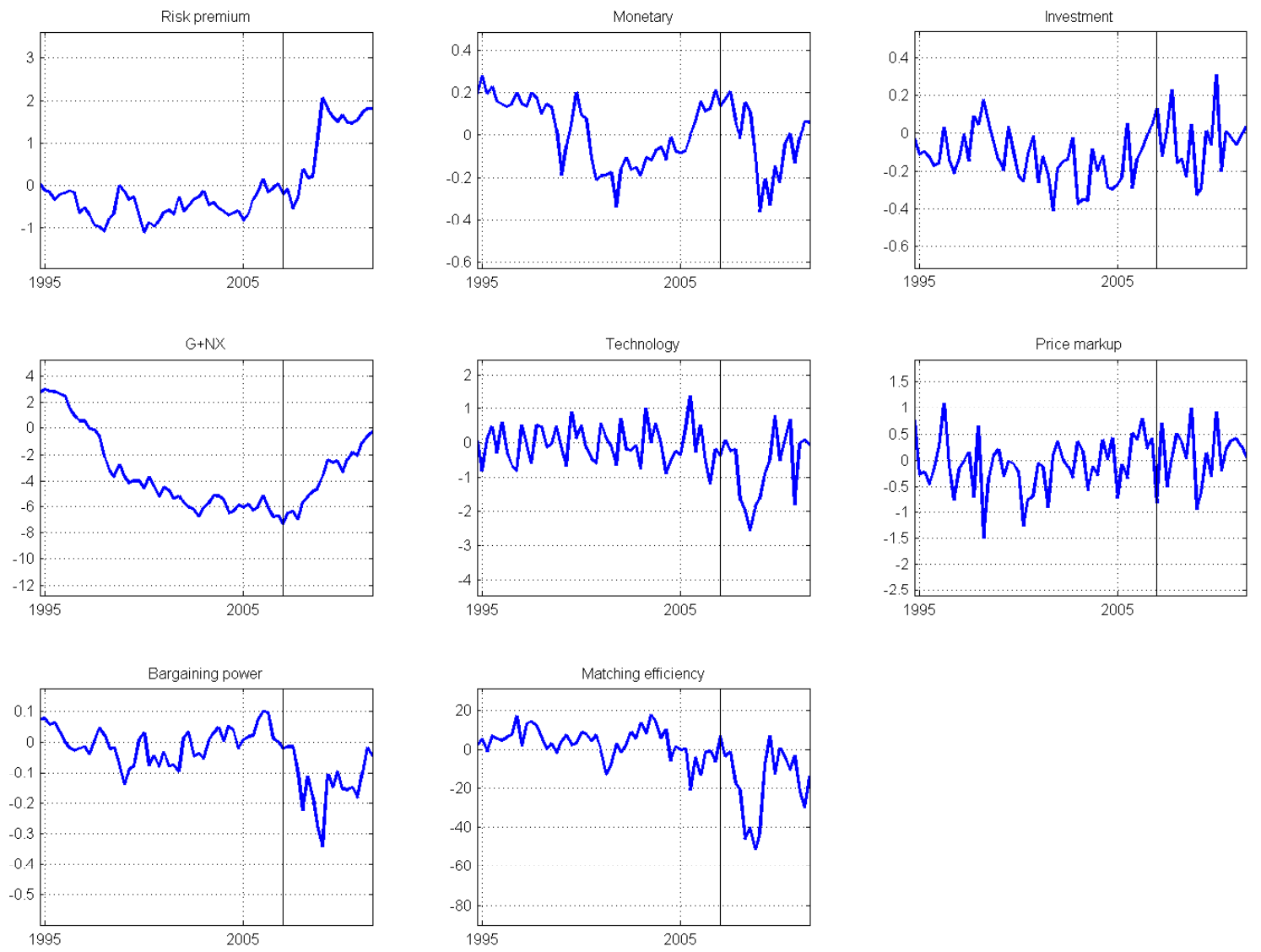

This figure shows the estimated time-series processes for the structural shocks in the U.K. The vertical line corresponds to 2007Q1, the last period in the sample used for estimation. 
Figure 6: Estimated shocks, Sweden
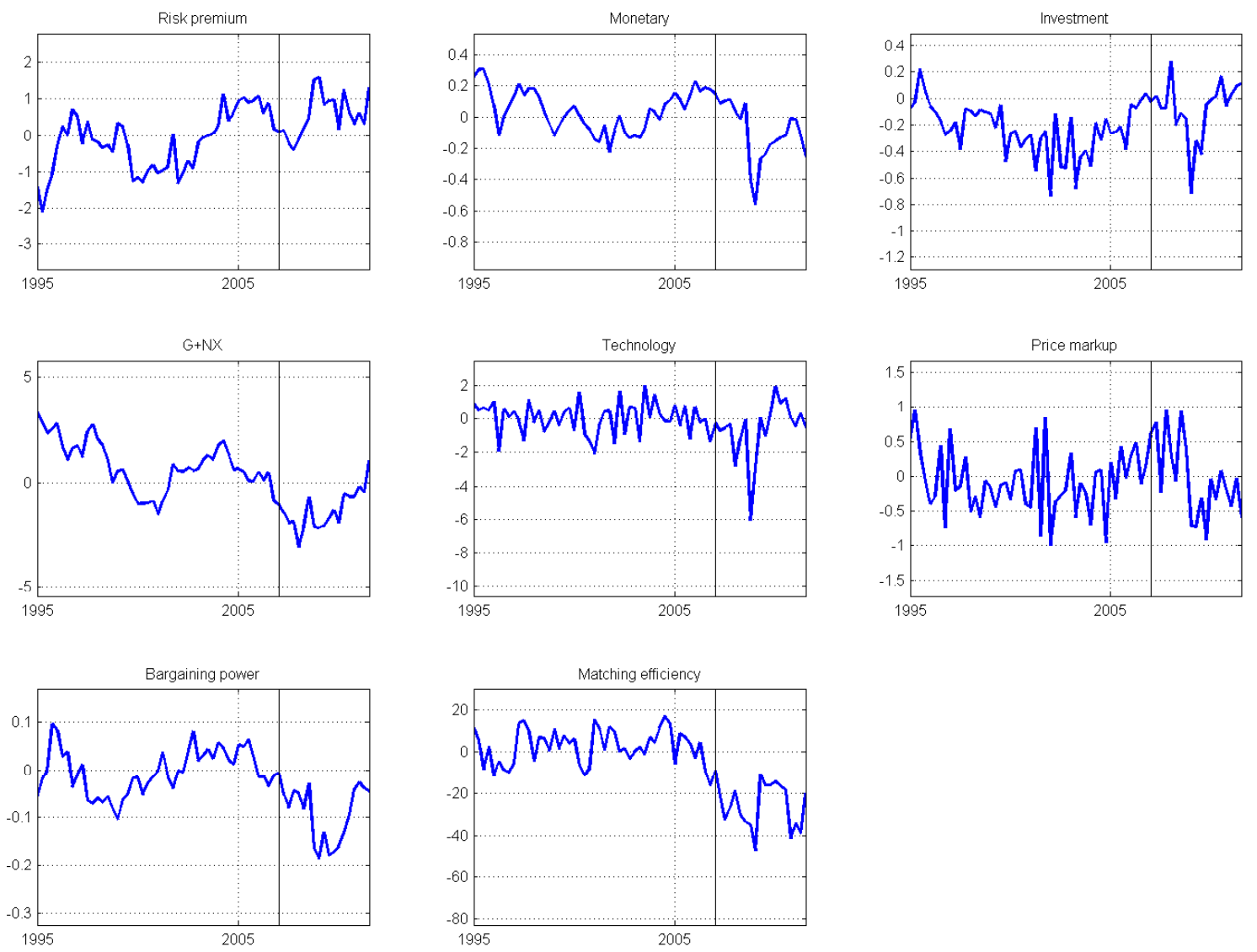

This figure shows the estimated time-series processes for the structural shocks in Sweden. The vertical line corresponds to 2007Q1, the last period in the sample used for estimation. 
Figure 7: Estimated shocks, Germany
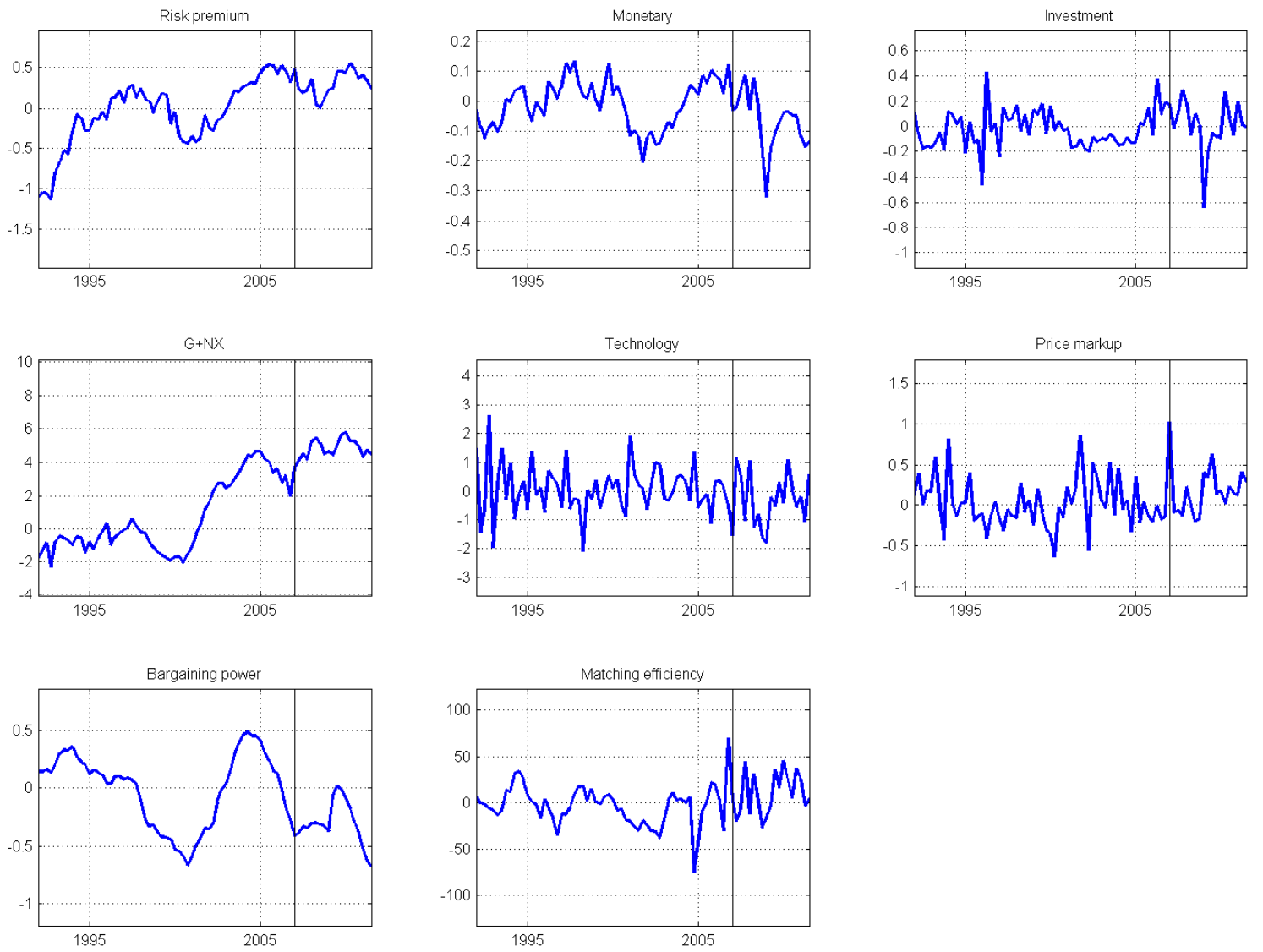

This figure shows the estimated time-series processes for the structural shocks in Germany. The vertical line corresponds to 2007Q1, the last period in the sample used for estimation. 
(a) US

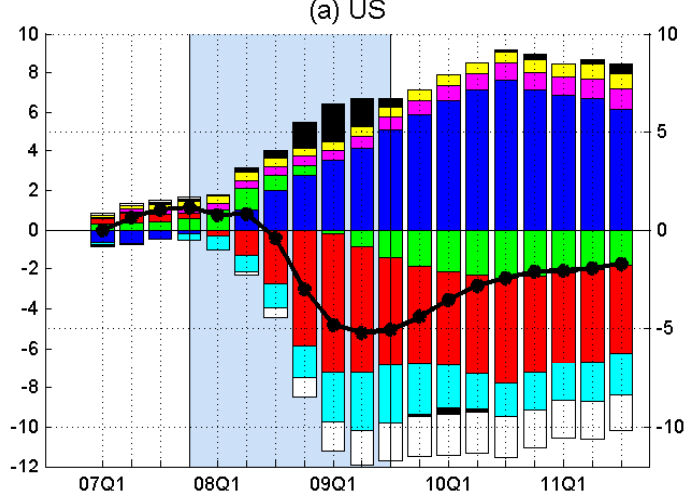

(c) Sweden

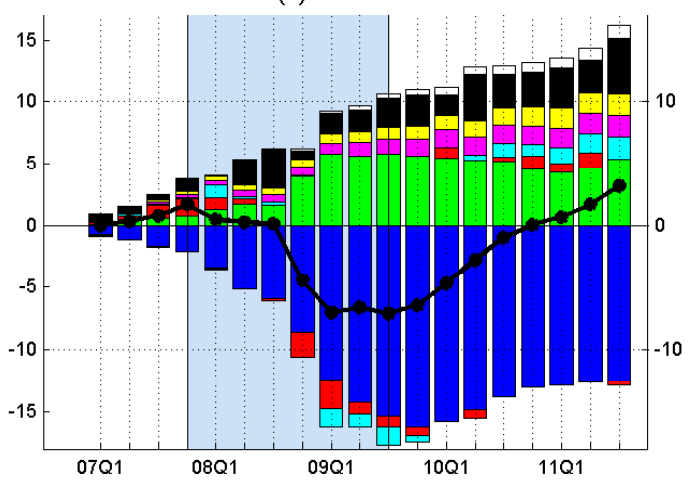

(b) UK

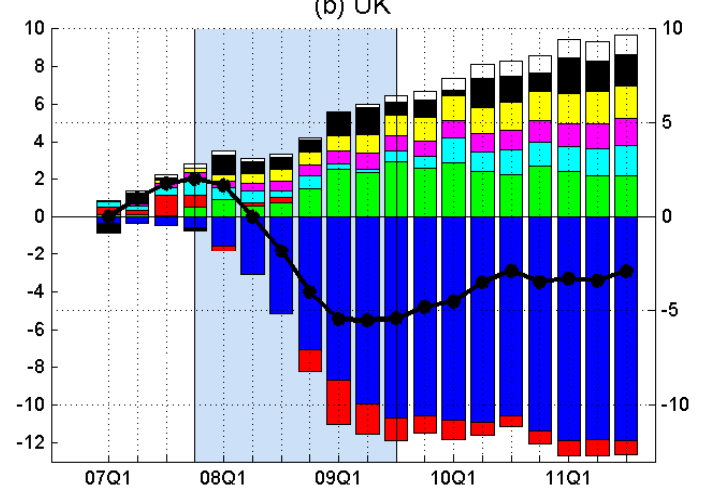

(d) Germany

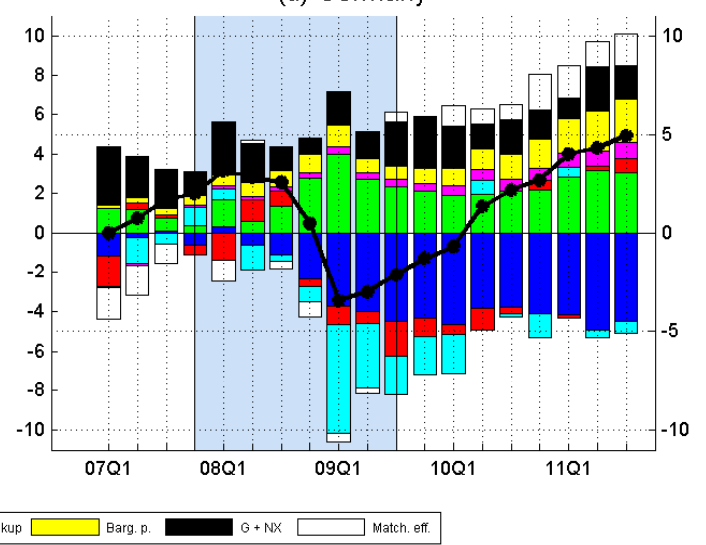

This figure shows decompositions of GDP in the period from 2007Q1 to 2011Q3 using the estimated models. The black line is cumulated GDP growth since 2007Q1 (read off the right-hand axis), the colored bars correspond to the contribution of each structural shock (read off the left-hand axis). 
Figure 9: Decomposing the unemployment rate, 2007-2011

(a) US

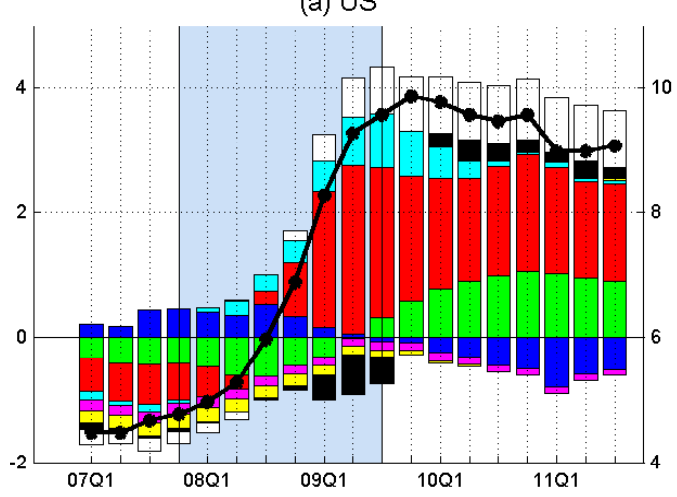

(c) Sweden

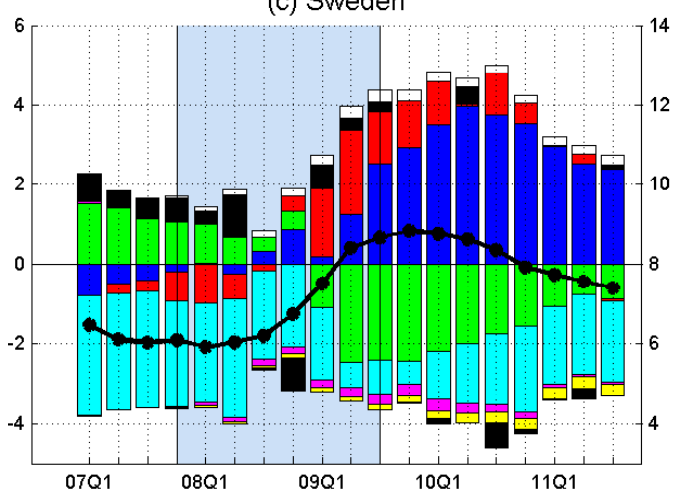

(b) UK

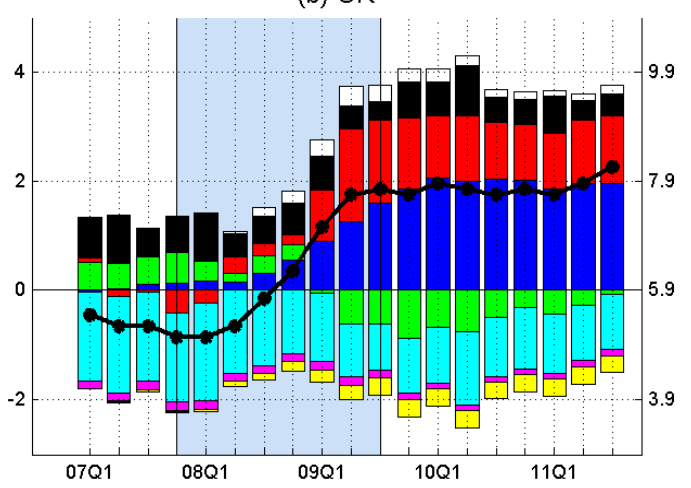

(d) Germany

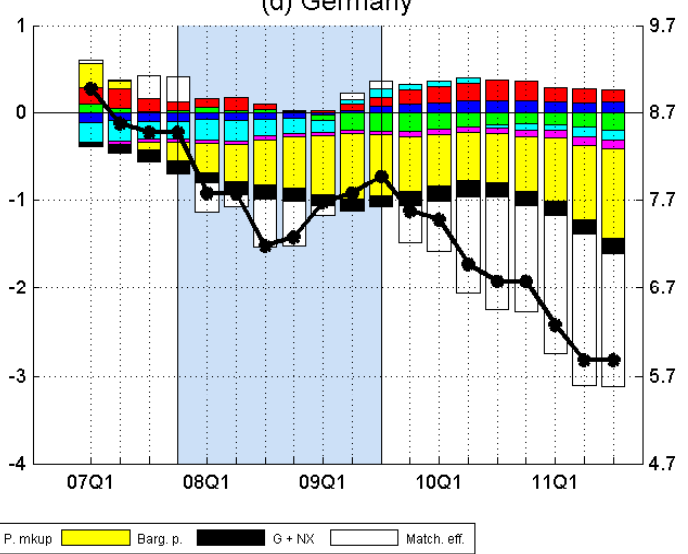

This figure shows decompositions of the rate of unemployment in the period from 2007Q1 to 2011Q3 using the estimated models. The black line is the rate of unemployment (read off the right-hand axis), the colored bars correspond to the contribution of each structural shock (read off the left-hand axis, expressed in percent deviation from steady state). 
Figure 10: Decomposing vacancies, 2007-2011
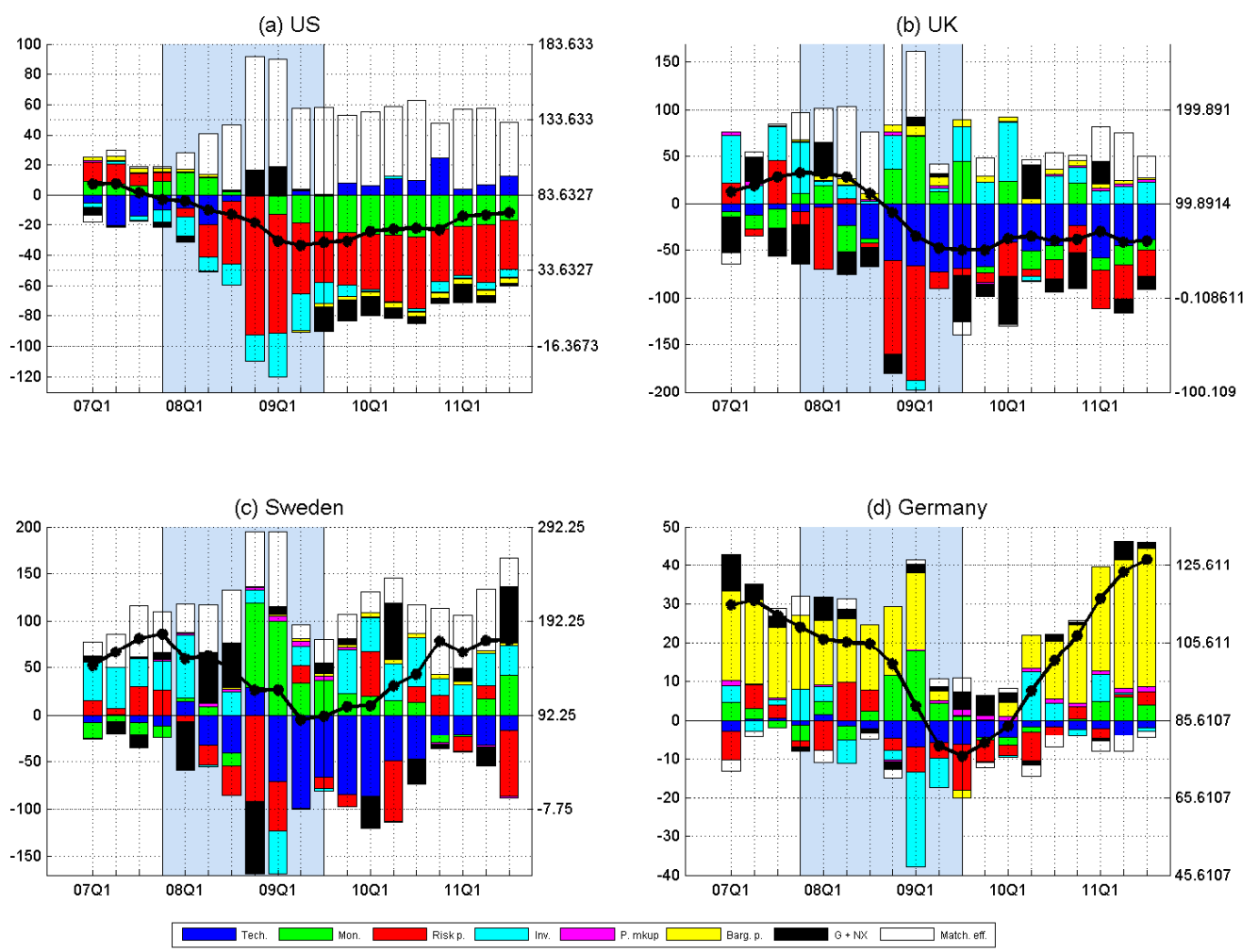

This figure shows decompositions of the level of vacancies in the period from 2007Q1 to 2011Q3 using the estimated models. The black line is the level of vacancies (read off the right-hand axis), the colored bars correspond to the contribution of each structural shock (read off the left-hand axis, expressed in percent deviation from steady state). 
(a) US

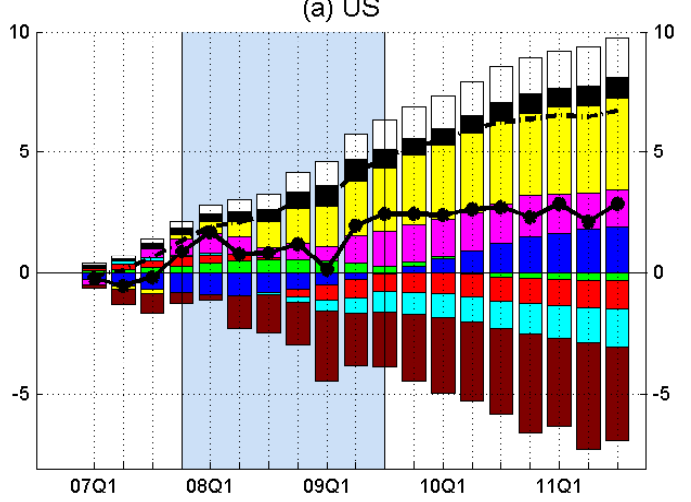

(c) Sweden

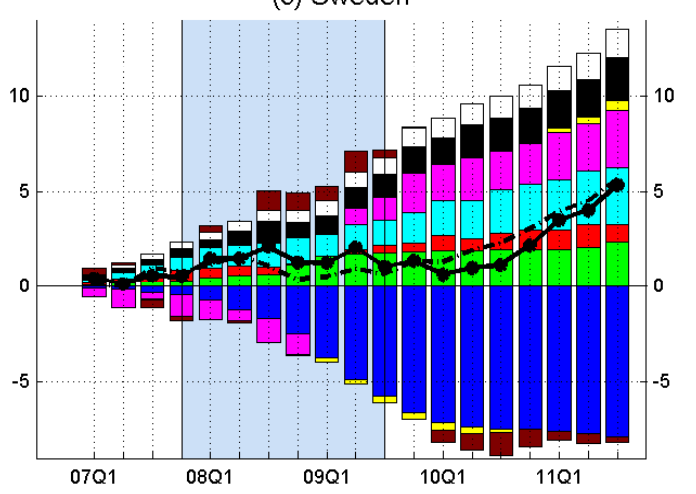

(b) UK

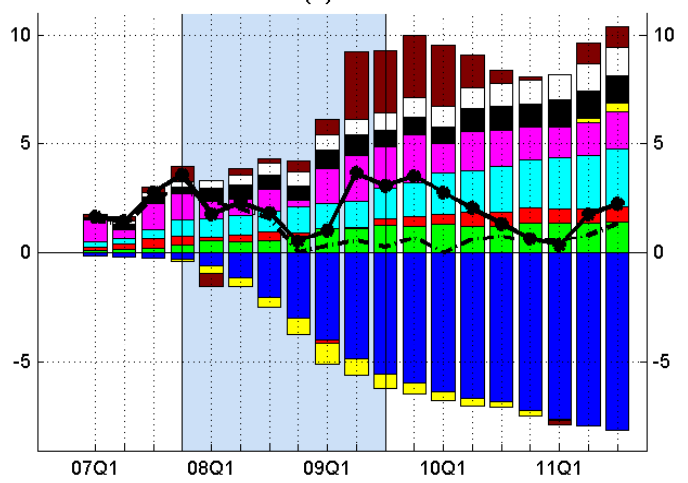

(d) Germany

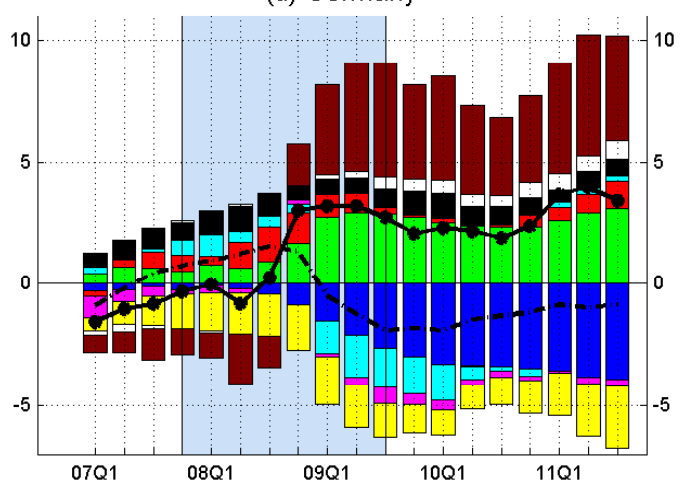

This figure shows decompositions of the cumulated real wage growth in the period from 2007Q1 to 2011Q3 using the estimated models. The black line is the cumulated real wage growth since 2007Q1 (read off the right-hand axis), the black dashed line is the cumulated real wage growth net of the measurement error, the colored bars correspond to the contribution of each structural shock (read off the left-hand axis). 
Figure 12: Decomposing the Okun's law relationship, U.S.
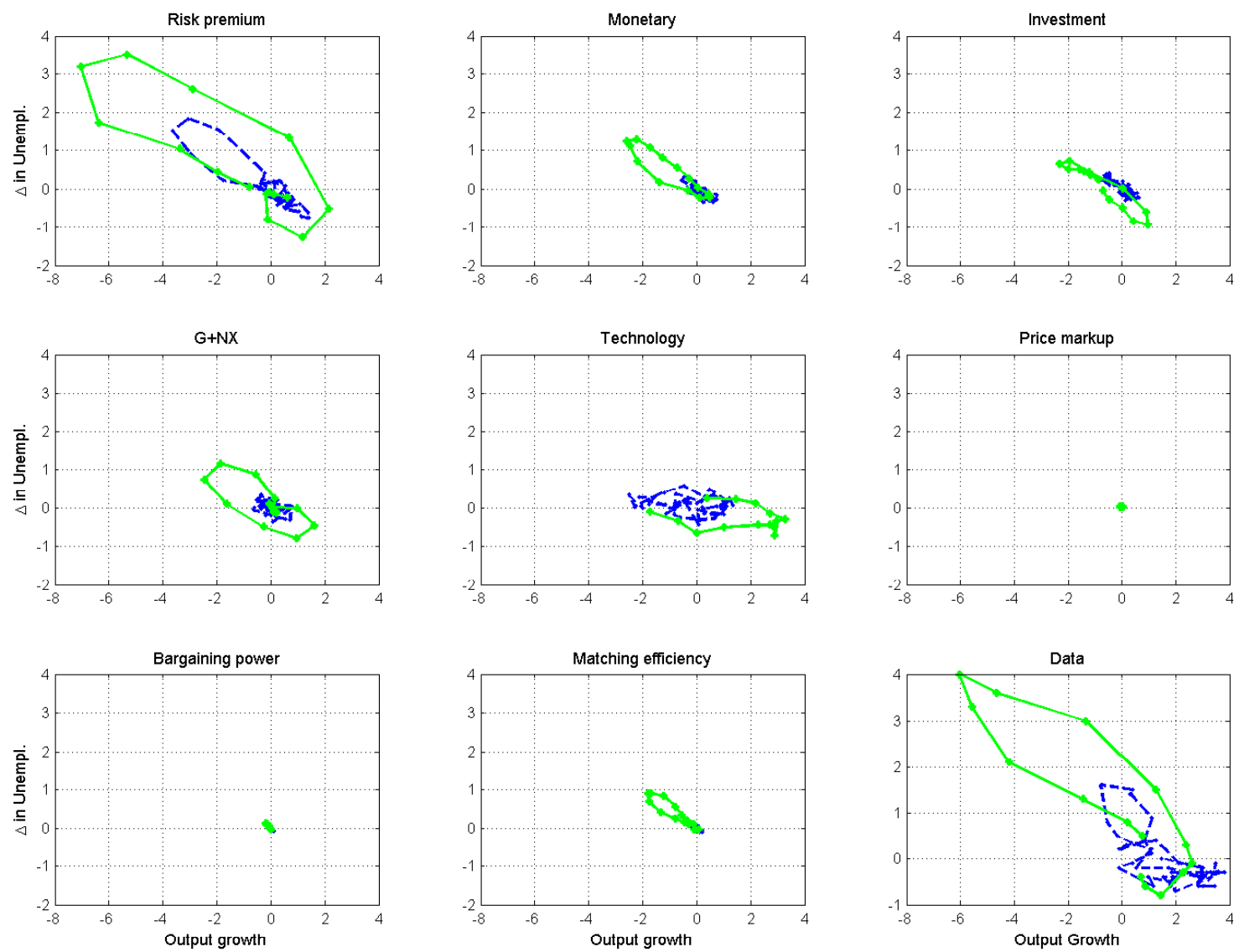

This figure shows a decomposition of the Okun's law relationship in the U.S. (the four-quarter growth rate of GDP against the four-quarter change in the unemployment rate) in the period from 1995Q1 until $2011 \mathrm{Q} 4$. The blue sections refer to the period 1995-2006, the green sections to 2007-2011. 
Figure 13: Decomposing the Okun's law relationship, U.K.
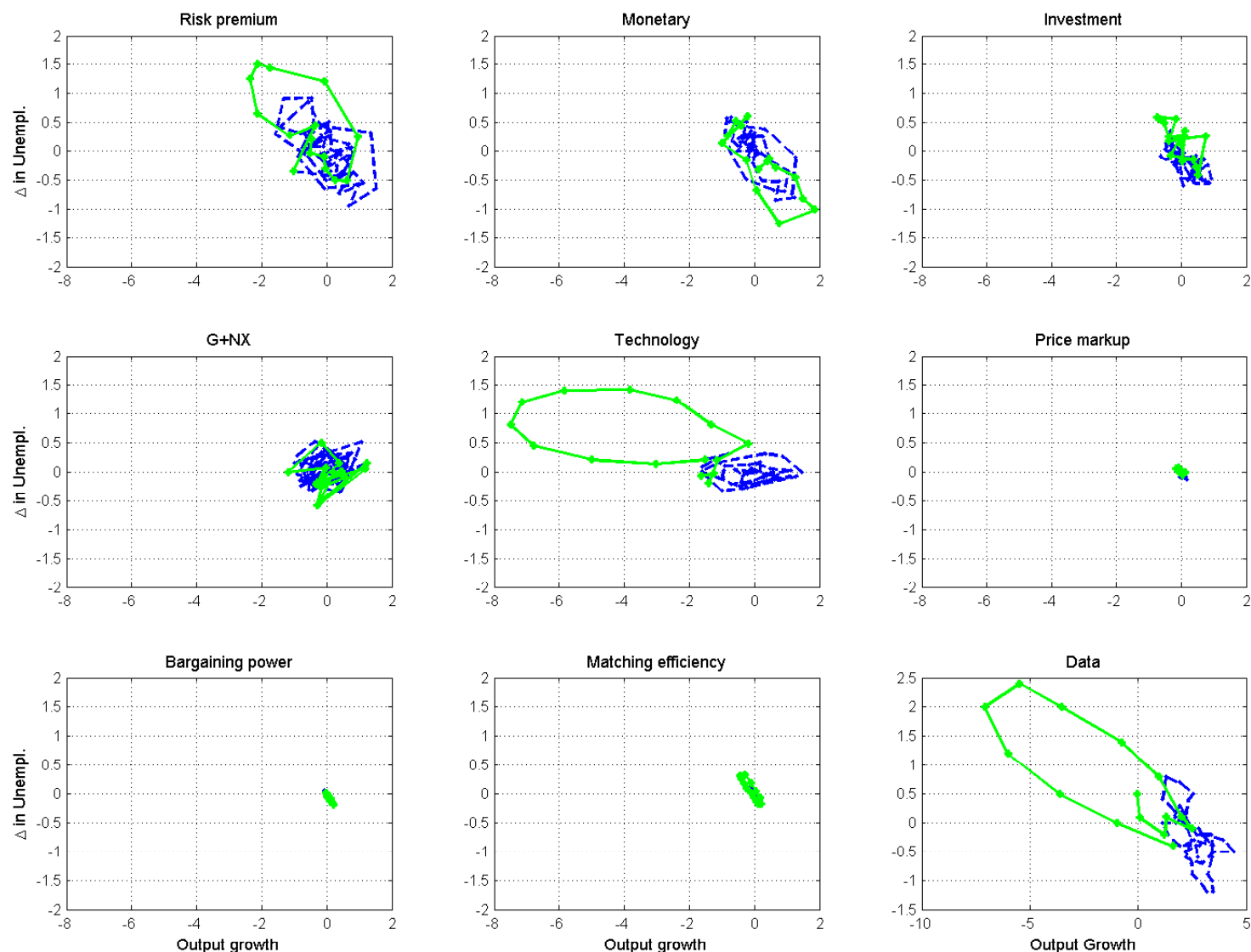

This figure shows a decomposition of the Okun's law relationship in the U.K. (the four-quarter growth rate of GDP against the four-quarter change in the unemployment rate) in the period from 1995Q1 until 2011 Q4. The blue sections refer to the period 1995-2006, the green sections to 2007-2011. 
Figure 14: Decomposing the Okun's law relationship, Sweden
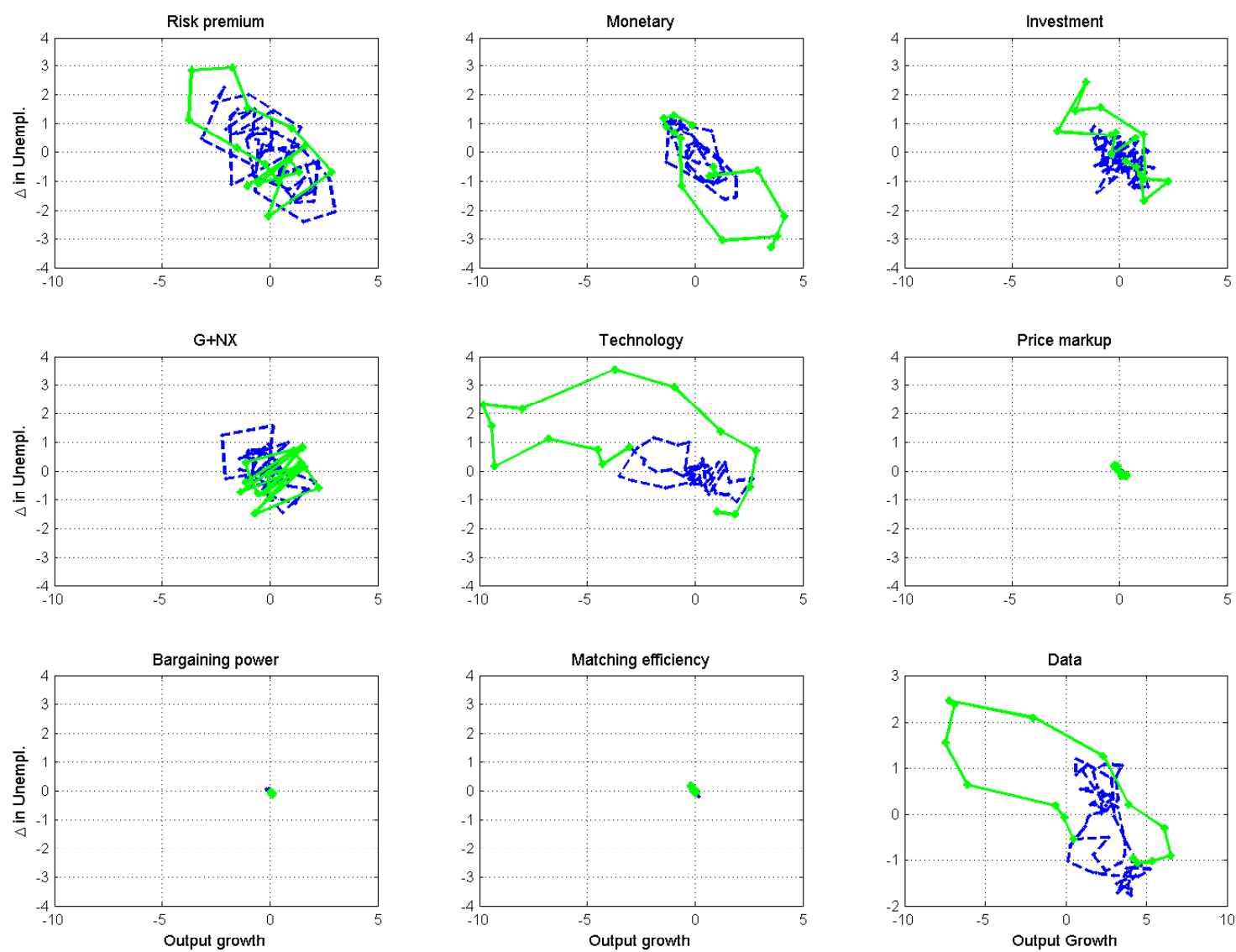

This figure shows a decomposition of the Okun's law relationship in Sweden (the four-quarter growth rate of GDP against the four-quarter change in the unemployment rate) in the period from 1995Q1 until 2011 Q4. The blue sections refer to the period 1995-2006, the green sections to 2007-2011. 
Figure 15: Decomposing the Okun's law relationship, Germany
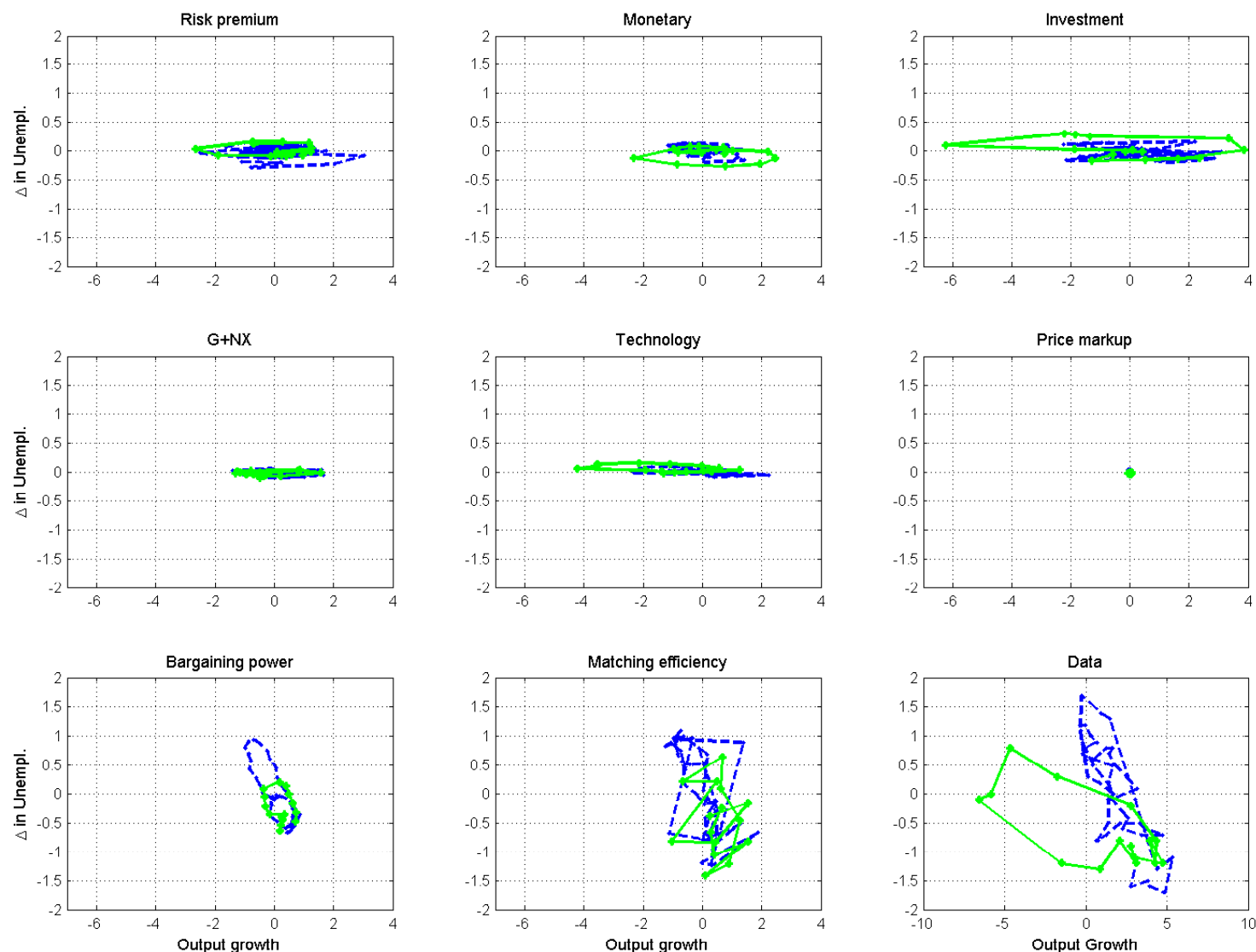

This figure shows a decomposition of the Okun's law relationship in Germany (the four-quarter growth rate of GDP against the four-quarter change in the unemployment rate) in the period from 1995Q1 until $2011 \mathrm{Q} 4$. The blue sections refer to the period 1995-2006, the green sections to 2007-2011. 
Figure 16: Decomposing the Beveridge curve, U.S.
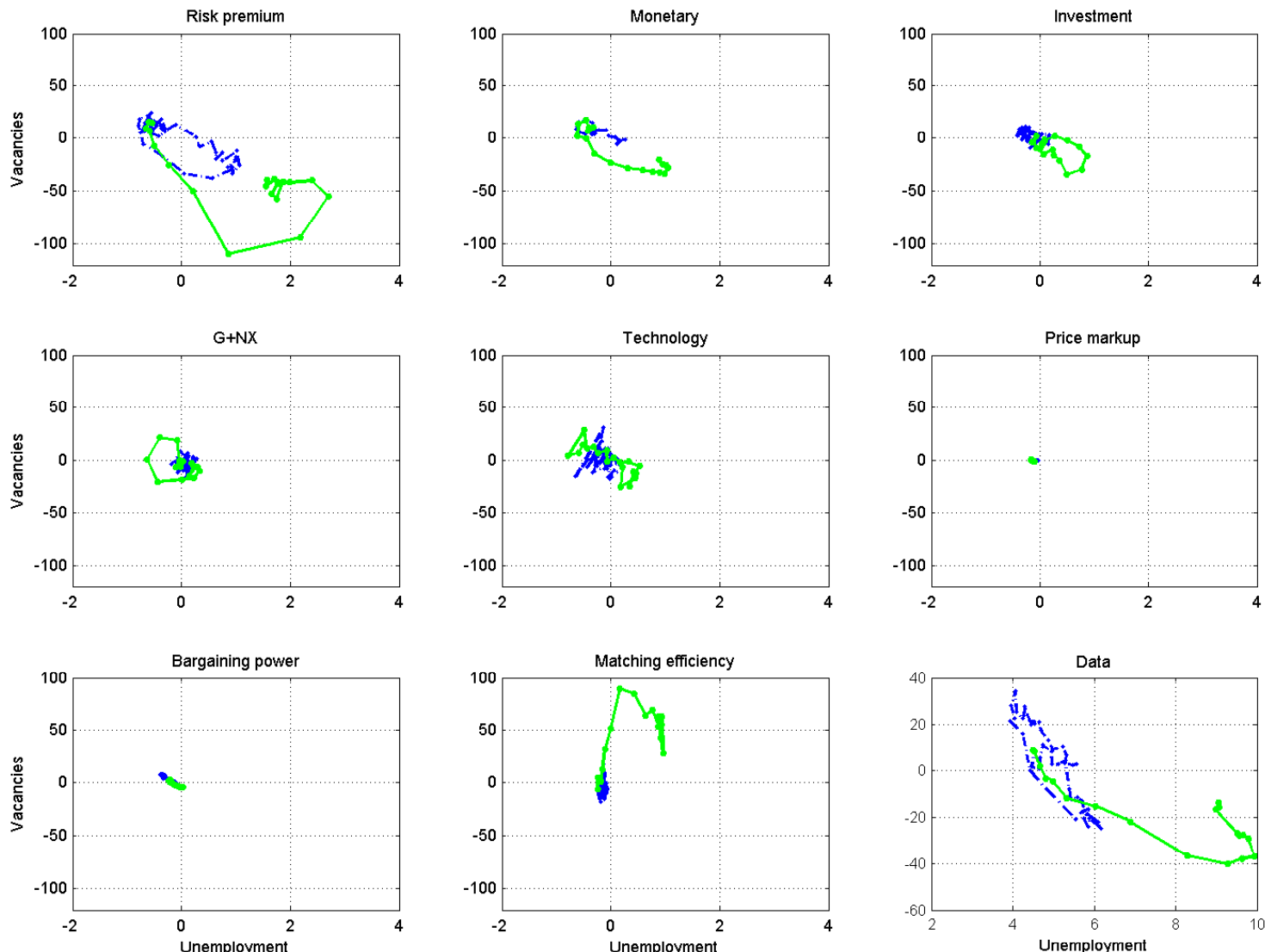

This figure shows a decomposition of the Beveridge curve in the U.S. (the rate of unemployment against the percent deviation of vacancies from the sample mean) in the period from 1995Q1 until 2011Q4. The blue sections refer to the period 1995-2006, the green sections to 2007-2011. 
Figure 17: Decomposing the Beveridge curve, U.K.
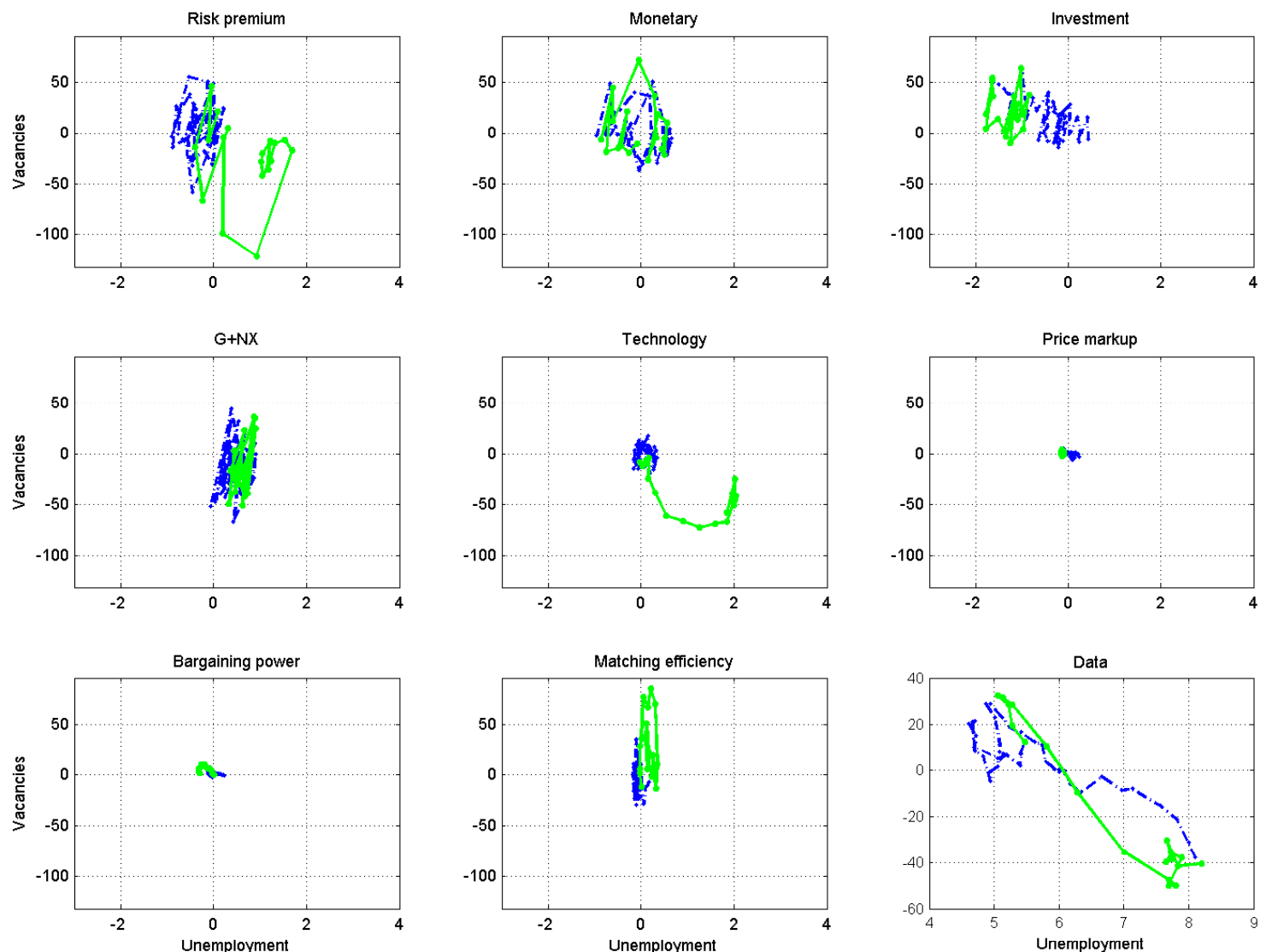

This figure shows a decomposition of the Beveridge curve in the U.K. (the rate of unemployment against the percent deviation of vacancies from the sample mean) in the period from 1995Q1 until 2011Q4. The blue sections refer to the period 1995-2006, the green sections to 2007-2011. 
Figure 18: Decomposing the Beveridge curve, Sweden
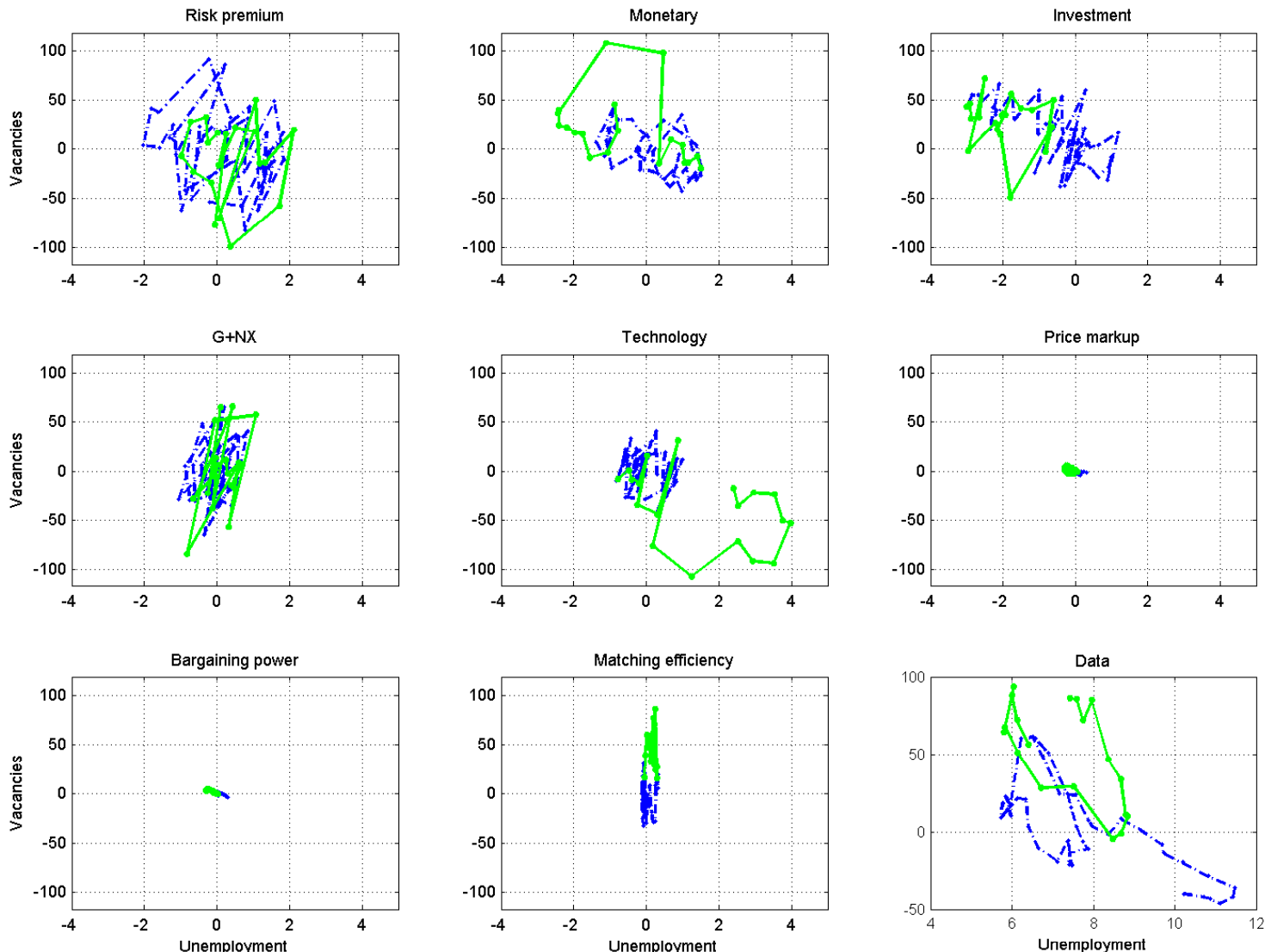

This figure shows a decomposition of the Beveridge curve in Sweden (the rate of unemployment against the percent deviation of vacancies from the sample mean) in the period from 1995Q1 until 2011Q4. The blue sections refer to the period 1995-2006, the green sections to 2007-2011. 
Figure 19: Decomposing the Beveridge curve, Germany
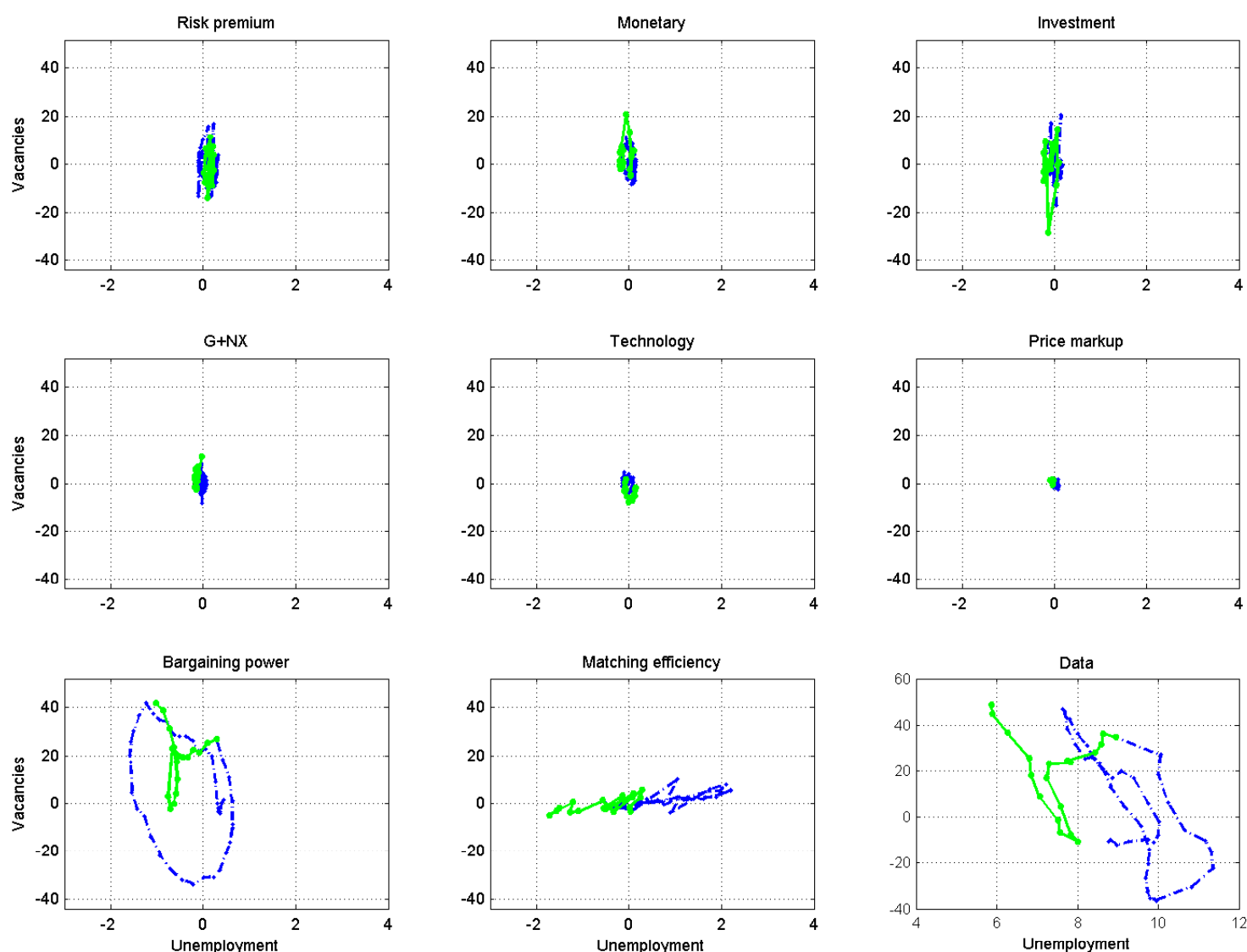

This figure shows a decomposition of the Beveridge curve in Germany (the rate of unemployment against the percent deviation of vacancies from the sample mean) in the period from 1995Q1 until 2011Q4. The blue sections refer to the period 1995-2006, the green sections to 2007-2011. 
Figure 20: Counterfactual developments of output and unemployment in Germany
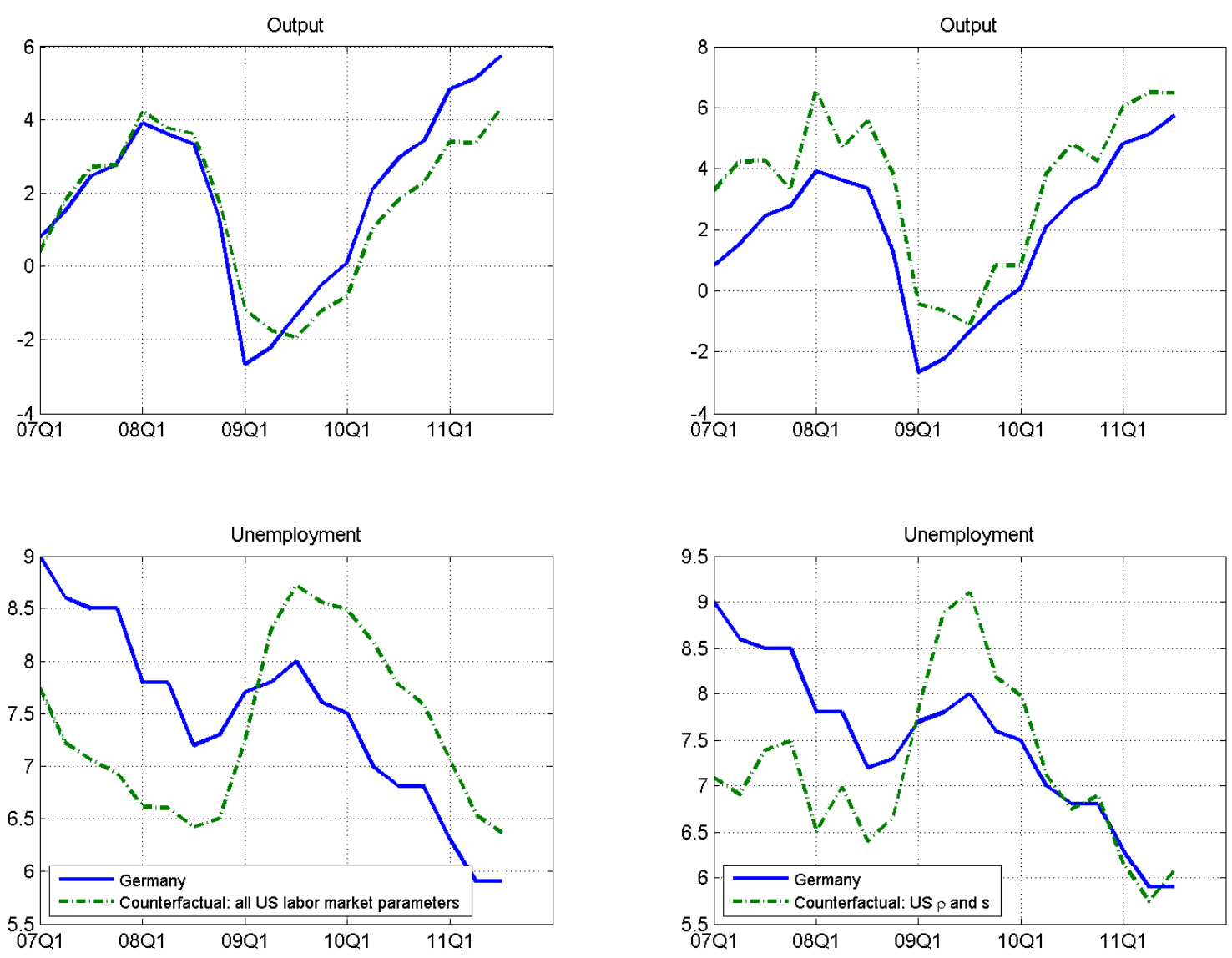

This figure shows the counterfactual development of output and unemployment in Germany with labor market parameters from the U.S. 